\title{
Fluoxetine rescues rotarod motor deficits in Mecp2 heterozygous mouse model of Rett syndrome via brain serotonin
}

Running title: Fluoxetine rescues motor deficits in Mecp2 ${ }^{+-}$mice

Claudia Villani ${ }^{1}$, Giuseppina Sacchetti ${ }^{1}$, Mirjana Carli ${ }^{1}$, Roberto W. Invernizzi ${ }^{1}$

${ }^{1}$ Laboratory of Neurochemistry and Behavior, Department of Neuroscience, Istituto di Ricerche Farmacologiche "Mario Negri" IRCCS, Milano, Italy

Correspondence should be addressed to Dr Roberto W. Invernizzi, Istituto di Ricerche Farmacologiche Mario Negri IRCCS, Via Mario Negri 2, 20156 Milano, Italy. Email:rinvernizzi@marionegri.it

Declaration of interest: none

Fundings: This research did not receive any specific grant from funding agencies in the public, commercial, or not-for-profit sectors

Abbreviations: 5-hydroxyindoleacetic acid, 5-HIAA; 8-hydroxy-di-n-propylamino tetraline, 8-OH-DPAT; analysis of variance, ANOVA; beam walking, BM; citalopram, CIT; fluoxetine, FLX; heterozygous, Het or Het; insulin growth factor-1, IGF-1 MethylCpG-binding protein 2, Mecp2; p-chlorophenylalanine, pCPA; Rett syndrome, RTT; rotarod, RR Selective serotonin reuptake inhibitors, SSRIs; serotonin, 5-HT; tryptophan hydroxylase-2, Tph2; vehicle, Veh; wild type, WT. 


\section{Abstract}

Motor skill is a specific area of disability of Rett syndrome (RTT), a rare disorder occurring almost exclusively in girls, caused by loss-of-function mutations of the Xlinked methyl-CpG-binding protein2 (MECP2) gene, encoding the MECP2 protein, a member of the methyl-CpG-binding domain nuclear proteins family. Brain 5-HT, which is defective in RTT patients and Mecp2 mutant mice, regulates motor circuits and SSRIs enhance motor skill learning and plasticity.

In the present study, we used heterozygous (Het) Mecp2 female and Mecp2-null male mice to investigate whether fluoxetine, a SSRI with pleiotropic effects on neuronal circuits, rescues motor coordination deficits. Repeated administration of $10 \mathrm{mg} / \mathrm{kg}$ fluoxetine fully rescued rotarod deficit in Mecp2 Het mice regardless of age, route of administration or pre-training to rotarod. The motor improvement was confirmed in the beam walking test while no effect was observed in the hanging-wire test, suggesting a preferential action of fluoxetine on motor coordination. Citalopram mimicked the effects of fluoxetine, while the inhibition of $5-\mathrm{HT}$ synthesis abolished the fluoxetine-induced improvement of motor coordination. Mecp2 null mice, which responded poorly to fluoxetine in the rotarod, showed reduced $5-\mathrm{HT}$ synthesis in the prefrontal cortex, hippocampus and striatum, and reduced efficacy of fluoxetine in raising extracellular 5-HT as compared to female mutants. No sex differences were observed in the ability of fluoxetine to desensitize $5-\mathrm{HT}_{1 \mathrm{~A}}$ autoreceptors upon repeated administration. These findings indicate that fluoxetine rescues motor coordination in Mecp2 Het mice through its ability to enhance brain 5-HT and suggest that drugs enhancing $5-\mathrm{HT}$ neurotransmission may have beneficial effects on motor symptoms of RTT.

Key words: Fluoxetine; Mecp2; Motor dysfunction; Rett syndrome; Serotonin; 


\section{Introduction}

Mutations of the methyl-CpG-binding protein2 (Mecp2), an X-linked gene, is the leading cause of Rett syndrome (RTT), a rare disease affecting females from the first/second year of life (Amir et al., 1999). Affected patients develop a variety of symptoms including motor and cognitive deficits, autistic-like features, convulsions and breathing irregularities (Chahrour and Zoghbi, 2007; Hagberg et al., 1983). Motor deficits, such as ataxia, apraxia and loss of motor skill are prominent in RTT and are consistently reproduced in mice with Mecp2 deletion or truncation regardless of the sex and background strain (Lombardi et al., 2015). Although hypotrophic fibers, disorganized morphology and altered insulin growth factor-1 signaling is found in muscles of Mecp2-null mice, specific deletion of Mecp2 in skeletal muscles does not reproduce these alterations suggesting that motor phenotype in RTT mice reflects non cell-autonomous mechanisms (Conti et al., 2015). Consistently, conditional deletion of Mecp2 in nervous tissue and in specific neuronal types of the mouse brain reproduced motor skill deficits typically observed in male Mecp2-null and heterozygous (Het) female mice (Chao et al., 2010; Ito-Ishida et al., 2015; Meng et al., 2016; Ure et al., 2016). Therapeutic targets and potential pharmacological strategies are currently being explored, but at present no cure or disease-modifying therapy is available for RTT (Katz et al., 2012). Studies aimed at restoring Mecp2 function in RTT adult mice through gene therapy, achieved nearly complete reversal of most symptoms including motor abnormalities in Mecp2-null and Mecp2 Het mice (Garg et al., 2013; Guy et al., 2007; Robinson et al., 2012) suggesting that therapeutic intervention for RTT patients can be effective even after symptoms onset. However, most of the pre-clinical studies testing potential pharmacological treatments for RTT did not achieved the complete recovery of motor function (Braun et al., 2012; 
Buchovecky et al., 2013; Krishnan et al., 2015; Mellios et al., 2014; Nag and BergerSweeney, 2007). Thus, the identification of better drugs for RTT is needed.

Low levels of brain serotonin $(5-\mathrm{HT})$, tryptophan hydroxylase-2 (Tph2), the ratelimiting enzyme in brain 5-HT synthesis, and cerebrospinal fluid 5-hydroxyindoleacetic acid (5-HIAA), the main 5-HT metabolite, are found in RTT patients (Riederer et al., 1985; Samaco et al., 2009; Zoghbi et al., 1989). Likewise, reduced levels of 5-HT and 5-HIAA are found in several brain regions of male Mecp2-null mice (Ide et al., 2005; Studies in conditional knock-out mice to remove Mecp2 gene specifically from serotonergic neurons indicate that the loss of Mecp2 causes a cell-autonomous reduction of brain 5-HT levels and Tph2 expression (Samaco et al., 2009).

5-HT regulates motor networks facilitating motor skill, motor cortex plasticity and motor output (Vitrac and Benoit-Marand, 2017). Selective 5-HT reuptake inhibitors (SSRIs) enhance motor skill learning and plasticity (Batsikadze et al., 2013; Gerdelat-Mas et al., 2005; Loubinoux et al., 2005), which are defective in RTT patients and Mecp2 mutant mice (De Filippis et al., 2015; FitzGerald et al., 1990). Increasing brain 5-HT with citalopram improves the $\mathrm{CO}_{2}$ chemosensitivity in Mecp2-null mice (Toward et al., 2013). In addition, fluoxetine enhances the levels of MeCP2 protein in several brain regions of the rat and in the hippocampus of Ts65Dn mice, a mouse model of Down syndrome (Cassel et al., 2006; Stagni et al., 2015). Thus, in the present study we set out to assess the efficacy of fluoxetine, a SSRI currently used in the therapy of depression, to rescue motor impairment, a specific area of disability of RTT, which can be reliably modeled in mice regardless of sex, age and type of mutation (Lombardi et al., 2015). The role of 5-HT in the motor effects of fluoxetine was assessed by investigating whether a) brain 5 - $\mathrm{HT}$ depletion by $\mathrm{p}$-chlorophenylalanine (pCPA) affected fluoxetine-induced motor improvement, b) citalopram, another SSRI 
bioRxiv preprint doi: https://doi.org/10.1101/2020.06.12.147876; this version posted June 12, 2020. The copyright holder for this preprint (which was not certified by peer review) is the author/funder, who has granted bioRxiv a license to display the preprint in perpetuity. It is made available under aCC-BY-NC-ND 4.0 International license.

structurally not related to and by far more selective than fluoxetine (Popik, 1999), mimicked the motor-improving effects of fluoxetine, c) sex-dependent alteration of 5HT synthesis, release and auto-inhibitory feed-back mechanism occurs under basal conditions and in response to acute and chronic administration of fluoxetine 


\section{Materials and Methods}

\subsection{Experimental design and statistical analysis.}

Test cohorts composed of Mecp2 Het $(n=209)$, Mecp2-null mice $(n=68)$ and respective WT (151 females and 64 males) littermate controls were used to assess the ability of fluoxetine and citalopram to counteract motor deficits caused by Mecp2 deletion using the accelerating rotarod, beam walking and hanging-wire-tests, and the role of 5-HT in fluoxetine action. The number of mice/group was established according to recommended guidelines (Katz et al., 2012; Kilkenny et al., 2010), and previous assessments in Mecp2-null mice (Villani et al., 2016). Mice were allocated to experimental groups by simple randomization using a freely available software (Statpages.org). Experimenters blind to treatment assignment, assessed motor performance in various behavioral tests.

The primary end-point of the study was to establish whether fluoxetine rescued motor deficit in the rotarod. All statistical analyses were performed by GraphPad Prism version 7.02 for Windows (GraphPad Software, CA) or StatView 5.0.1 (SAS Institute, NC) and all data were expressed as mean \pm SEM. For rotarod data, statistical analysis was applied to the mean latency to fall on four daily trials. Two-way ANOVA, followed by Sidak's test was used to assess the effect of genotype, treatment and their interaction on the latency to fall from rotarod and the number of slips in the beam walking test. Repeated measures ANOVA, with genotype and treatment as betweensubject factors and days on treatment as within-subject factor, followed by two-way ANOVA at single time points was used to analyze the onset of fluoxetine effect on the rotarod. The effects of training on the rotarod in naïve Mecp2 Het and WT mice, the effects of fluoxetine on extracellular 5-HT and 8-OH-DPAT-induced hypothermia was also analyzed by repeated measures ANOVA with genotype or sex and treatment as between-subject factors and time as within-subject factor. Gaussian distribution was 
formally tested only for rotarod data, the primary end-point of the study, with the D'Agostino-Pearson normality test included in the Graph Pad Prism 7.02 package (D’Agostino, 1986). The analysis confirmed the normal distribution of the latency to fall data with the exception of rotarod data obtained in mice given $20 \mathrm{mg} / \mathrm{kg}$ fluoxetine in which $n<8$ precluded the application of the test. A small departure from normality was observed for the group of mice treated with vehicle + pcpa $(p=0.0304)$. The scores obtained in the hanging-wire test were compared by Dunn's test for comparison between single means. Differences in 5-HTP accumulation between WT and mutant mice were assessed by Student's t-test.

\subsection{Mice breeding and husbandry}

Mecp2 Het female $\left(\mathrm{Mecp}^{-/+}\right)$and WT male $\left(\mathrm{Mecp}^{+/ \mathrm{y}}\right)$ mice on C57BL/6J background were purchased from The Jackson Laboratory (Bar Harbor, ME). As Mecp2-null mice do not mate, breeding pairs were composed by female Mecp2 Het and C57BL/6J male mice from the colony, in a 2:1 ratio, to generate all the genotypes needed in the experiments. Mice were maintained in a specific pathogen free animal facility under a $12 \mathrm{~h}$ light/dark cycle (light on at 7:00 a.m.) at $21 \pm 2^{\circ} \mathrm{C}$ and $55 \pm 5 \%$ relative humidity, with food (Teklad Global 2018S; Envigo, Udine, Italy) and filtered tap water freely available. At weaning, mice were genotyped using standard procedures, separated and group-housed according to sex and provided with environmental enrichment consisting of a colored plastic shelter in each home cage. Nesting material (wood-wool) was provided to breeding cages.

\subsection{Ethical statement}

The "Istituto di Ricerche Farmacologiche Mario Negri IRCCS" adheres to the principle set out in the following law, regulations, and policies governing the care and use of 
laboratory animals: Italian Governing Law (D.Igs.26/2014; Authorization n. 19/2008-A issued March 6, 2008 by Ministry of Health); "Mario Negri" Institutional Regulations and Policies providing internal authorization for persons conducting animal experiments (Quality Management System Certificate - UNI EN ISO 9001:2008 - Reg. N 6121); the NIH Guide for the Care and Use of Laboratory Animals (2011 edition) and EU directives and guidelines (EEC Council Directive 2010/63/UE).

\subsection{Rotarod}

Mice were pre-trained on the rotarod (Ugo Basile, Gemonio, Italy) at 5 weeks of age (four daily trials for 3 consecutive days; $4-40 \mathrm{rpm}$ in $300 \mathrm{~s}$ ). At the end of each trial, mice were returned to the home cage for at least 15 min resting before the next trial. The same procedure was used in the test sessions. A cohort of pre-trained mice (21 WT and 24 Mecp2 Het), was used to assess the effect of 14-day treatment with fluoxetine. A second cohort of pre-trained Mecp2 Het $(n=32)$ and WT $(n=21)$ mice was repeatedly exposed to daily rotarod session $2 \mathrm{~h}$ and $24 \mathrm{~h}$ and 3,7 and 14 days after treatment. These mice were also assessed in the hanging-wire test. Another cohort of Mecp2 Het mice, repeatedly injected with fluoxetine or water for 17 days, received pCPA from day 15 to 17 and were tested in the rotarod $24 \mathrm{~h}$ after the last dose of pCPA (44 Mecp2 Het). Twenty-one Het and 21 WT female mice were treated with citalopram in the drinking water or plain water and assessed in the rotarod and beam walking test after 14 and 15 days of treatment, respectively.

Because of the short life span and early onset of the motor deficits, male Mecp2 null mice $(n=37)$ and WT $(n=37)$ were not pre-trained on the rotarod but tested immediately before the beginning of fluoxetine treatment and after 14 days of treatment. Except if 
otherwise specified, all mice were tested on the rotarod about $24 \mathrm{~h}$ after the last dose of the chronic schedule.

Three separate cohort of mice were used to investigate sex-related difference in 5-HT synthesis (7 WT and 6 Mecp2-null male mice and 6 WT and 6 Mecp2-het female mice); the effects of fluoxetine on extracellular 5-HT (9 WT and 10 Mecp2-null male mice and 9 WT and 11 Mecp2-het female mice) and the hypothermic response to 8-OH-DPAT (12 WT and 13 Mecp2-null male mice and 14 WT and 11 Mecp2-het female mice).

\subsection{Beam walking}

A wood plank with a flat surface $8 \mathrm{~mm}$ wide and $80 \mathrm{~cm}$ long, resting on 2 poles $(50 \mathrm{~cm}$ above the ground) was used. Training consisted in two consecutive sessions during which mice were positioned at one end of the beam and allowed to cross the beam length, with gentle guiding or prodding as needed, until they cross readily. On the test phase, the number of slips is recorded on 3 consecutive trials, with an intertrial interval of at least $15 \mathrm{~min}$.

\subsection{Hanging-wire}

A stainless steel wire $2 \mathrm{~mm}$ thick and $640 \mathrm{~mm}$ long was suspended horizontally to two vertical stands at $30 \mathrm{~cm}$ height above the ground. A mouse was handled by the tail, suspended by the forelimbs on the middle of the wire and the timer started. When the animal reached one of the platforms positioned at the ends of the wire the timer was stopped and a second trial was started by hanging the mouse on the middle of the wire. If the animal fell, the timer was stopped, the initial score (ten) was diminished by 1 and the procedure was restarted. The test lasted for $180 \mathrm{~s}$ or for a maximum of 10 falls. 


\subsection{Drug treatment}

Fluoxetine (Casen, Recordati SL, Spain) was purchased from a local pharmacy, dissolved in pyrogen-free water $(10 \mathrm{~mL} / \mathrm{kg}$ ) and injected intraperitoneally (i.p.) at 10 or $20 \mathrm{mg} / \mathrm{kg}$ (as salt), between 8:00 and 10:00 AM, during the light phase of the light-dark cycle, starting on postnatal day (P) 35 in males and on P63 or P77 in females. Two different groups of mice were given fluoxetine $(10 \mathrm{mg} / \mathrm{kg} /$ day $)$ or citalopram (20 $\mathrm{mg} / \mathrm{kg} / \mathrm{day}$ ) in drinking water. Mean liquid intake was similar in mice receiving fluoxetine, citalopram or plain water $(3.6 \pm 0.2,4.1 \pm 0.1$ and $3.9 \pm 0.2 \mathrm{~mL} /$ day, respectively). This information and the measurement of average body weight for each genotype, were used to determine the drug concentration required to provide the established daily doses. Assessment of the stability of drug solutions showed no changes over 3 weeks storage at room temperature in drinking bottles (data not shown). pCPA ethylester hydrochloride (100 mg/kg of the free base; Sigma-Aldrich, Italy) was dissolved in water and administered by gavage from day 15 to 17 of repeated fluoxetine treatment, with the last dose of both drugs given $24 \mathrm{~h}$ prior to behavioral testing. A timeline of treatment schedules and behavioral assessment is provided in each figure.

\subsection{5-HTP assays}

Brain samples were homogenized in 10 volumes of $0.1 \mathrm{M} \mathrm{HClO}_{4}$ containing $0.1 \%$ $\mathrm{Na}_{2}$ EDTA and $0.05 \% \mathrm{Na}_{2} \mathrm{~S}_{2} \mathrm{O}_{5}$, stored in minced ice for 30 min and centrifuged at $10000 \mathrm{rpm}$ for $10 \mathrm{~min}$ with a Sigma 1-13 centrifuge (Celbio, Italy). Supernatant was 
filtered through $0.45 \mu \mathrm{m}$ syringe filter (Perkin Elmer, Italy) and injected into the HPLC coupled to electrochemical detection. 5-HTP was separated by a reverse phase column (Supelcosil LC18-DB $3 \mu \mathrm{m}, 75$ x 3 mm, Supelchem, Italy) with a mobile phase consisting of $88 \mathrm{mM} \mathrm{NaH}_{2} \mathrm{PO}_{4}$ monohydrate (VWR, Italy); $0.4 \mathrm{mM}$ sodium octan sulfonate (Sigma, Italy); $0.3 \mathrm{mM} \mathrm{Na} 2$ EDTA (Sigma, Italy). The $\mathrm{pH}$ of the solution was adjusted to 2.8 with $85 \% \mathrm{M} \mathrm{H}_{3} \mathrm{PO}_{4}$ after the addiction of $7 \% \mathrm{CH}_{3} \mathrm{OH}$. The mobile phase was pumped with a LC-20AD (Shimadzu, Italy) isocratic pump at $0.5 \mathrm{~mL} / \mathrm{min}$. The electrochemical detector (Coulochem II; ESA, MA, USA) was equipped with a 5011 analytical cell $\left(E_{1}=0 \mathrm{mV} ; E_{2}=+350 \mathrm{mV}\right)$.

\subsection{Intracerebral microdialysis}

Concentric dialysis probes were made with Cuprophan membrane (216- $\mu \mathrm{m}$ outer diameter, 3,000 Da cutoff, Sorin Biomedica, Italy), essentially as described elsewhere (Robinson and Whishaw, 1988). The membrane exposed to the brain tissue was $3 \mathrm{~mm}$ long. Female mice were anesthetized with ketamine/medetomidine 75/1 (mg/kg i. p.) or $3 \%$ isoflurane, while most male mice were anesthetized with $3 \%$ isoflurane for a rapid recovery post-anesthesia. Mice were positioned on a stereotaxic frame (model 900; Kopf Instruments, USA) and the dialysis probe was lowered into the mPFC and secured to the skull with anchorage screws and dental cement. The stereotaxic coordinates referred to the tip of the probe were: $A P+3.7$ and $L \pm 0.7 \mathrm{~mm}$ from bregma and DV $-4.8 \mathrm{~mm}$ from dura surface (Franklin and Paxinos, 1997). About $20 \mathrm{~h}$ after surgery, the probes were perfused with artificial cerebrospinal fluid (composition in mM: $\mathrm{NaCl} 140, \mathrm{CaCl}_{2}$ 1.26, $\mathrm{KCl} 3, \mathrm{MgCl}_{2}$ 1, $\mathrm{Na}_{2} \mathrm{HPO}_{4}$ 1.2, glucose 7.2; $\mathrm{pH} 7.4$ with 0.6 $\mathrm{M} \mathrm{NaH}_{2} \mathrm{PO}_{4}$ ) at $1 \mu \mathrm{l} / \mathrm{min}$ with a CMA/100 pump (CMA Microdialysis AB, Sweden). Once the extracellular 5-HT concentrations were stable (at least three consecutive samples 
differing less than $20 \%$ from the mean basal value), mice were given a challenge dose of fluoxetine (10 mg/kg i.p.). Samples of dialysate were collected every $20 \mathrm{~min}$ in autosampler vials containing $2 \mu \mathrm{L}$ of an antioxidant mixture (composition: acetic acid $0.1 \mathrm{M}, \mathrm{Na} 2 \mathrm{EDTA} 0.27 \mathrm{mM}$, L-cysteine $3.3 \mathrm{mM}$, ascorbic acid $0.5 \mathrm{mM}$; dilution 1:50) and stored at $5^{\circ} \mathrm{C}$ until analysis. $5-\mathrm{HT}$ in the dialysate was measured by HPLC coupled to electrochemical detection, (Invernizzi, 2013).

\subsection{8-OH-DPAT-induced hypothermia}

8-OH DPAT is a selective $5-\mathrm{HT}_{1 \mathrm{~A}}$ receptor agonist causing hypothermia mediated by the stimulation of $5-\mathrm{HT}_{1 \mathrm{~A}}$ autoreceptors (Goodwin et al., 1985). To assess the sensitivity of $5-\mathrm{HT}_{1 \mathrm{~A}}$ auto-receptors after repeated treatment with fluoxetine, Mecp2null, Mecp2 Het and WT mice received $0.2 \mathrm{mg} / \mathrm{kg}$ 8-OH DPAT subcutaneously (s.c). This dose was chosen on the basis of a dose-response curve (data not shown) because it causes an intermediate reduction of body temperature that allow to detect either potentiation or reduction of 8-OH-DPAT effects. Core temperature was measured by a BAT-12 Microprobe Thermometer equipped with a RET-3 rectal probe for mice (Physitemp, USA), every 15 minutes over a $2 \mathrm{~h}$ period. Temperature measurements were taken between 8:00 and 12:00 A.M. 
bioRxiv preprint doi: https://doi.org/10.1101/2020 06.12 147876; this version posted June 12 2020. The copyright holder for this preprint (which was not certified by peer review) is the author/funder, who has granted bioRxiv a license to display the preprint in perpetuity. It is made available under aCC-BY-NC-ND 4.0 International license.

\section{Results}

3.1 Effect of pre-training in the rotarod and age-dependent deficits in the rotarod and hanging-wire tests in Mecp2 Het and WT mice

Five weeks old Mecp2 Het and WT mice rapidly learned the accelerated rotarod task (Fig. 1A). Repeated measures ANOVA applied to the mean latency to fall of the 4 daily trials (Fig. 1B) showed significant effect of days $(F(2,126)=11.82, p<0.0001)$, but not genotype $(F(1,126)=3.483, p=0.0643)$ and interaction between days and genotype $(F(2,126)=0.3606, p=0.698)$ indicating that the ability to learn the task was not significantly affected by Mecp2 gene deletion in young Mecp2 Het mice. Post-hoc analysis showed a significant increase in the latency to fall between day 1 and 2 and day 1 and 3 of training, while no significant differences were observed between day 2 and 3 (Fig. 1B).
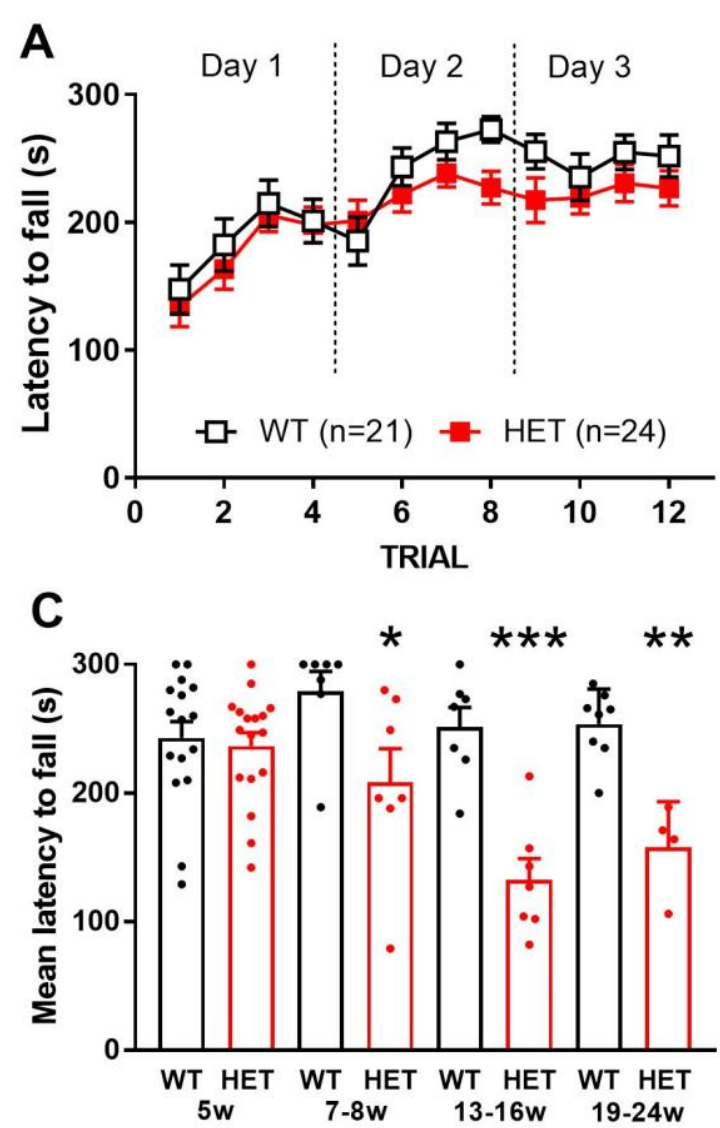

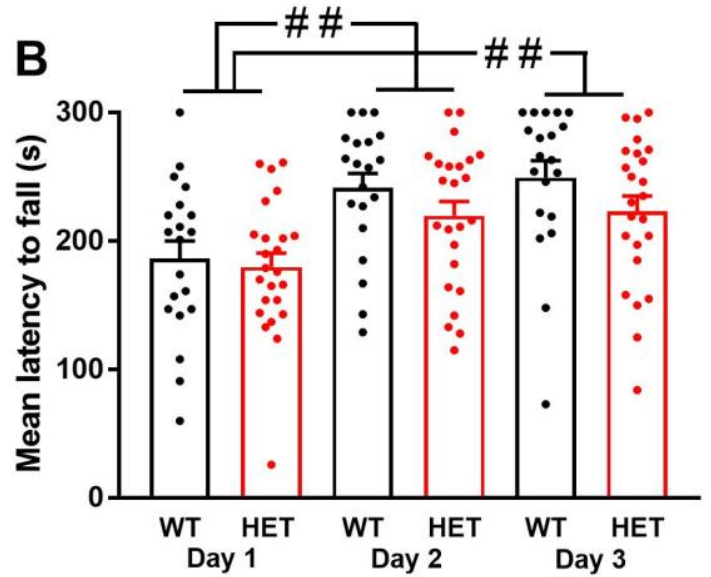

D

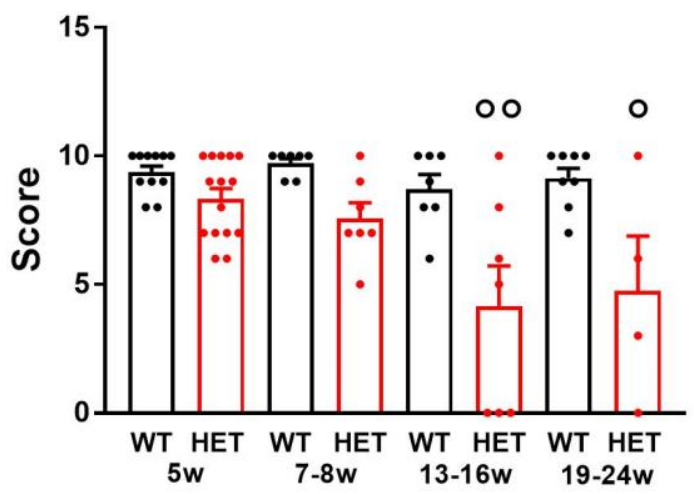


Fig. 1 Effect of repeated training on the rotarod and age-dependent performance of untreated WT and Mecp2 Het mice in the rotarod and hanging-wire tests.

Panel A describes the trial by trial improvement in latency to fall over 3 consecutive days of training on the rotarod, in 5 weeks old WT and Mecp2 Het (HET) female mice. Analysis of the mean latency to fall (panel B) show a significant improvement in performance between day 1 and 2, day 1 and 3 , but no differences between day 2 and 3 in both genotypes. Panels $C$ and D show the age-dependent performance of WT and Mecp2 Het mice in the rotarod and hanging-wire test, respectively. Different group of mice were used for each age. Data in panels $C$ and $D$ are the mean \pm SEM of 3 consecutive days of trials ( 4 trials/day). Black and red dots and histograms in panels $B, C$ and $D$ represent individual data points and the mean performance of the group, respectively. The number of mice per group is shown in parentheses. $\# p=0.0005$; \#\#p $<0.0001$ vs. day 1 (Sidak's test). ${ }^{*} p=0.0222,{ }^{* *} p=0.0045,{ }^{* * *} p<0.0001$ vs. WT; ${ }^{\circ} p$ $=0.0034,{ }^{\circ \circ} \mathrm{p}=0.0004$ vs. WT (Sidak's test).

Using different groups of Mecp2 Het and age-matched WT mice for each age range, we observed an age-dependent worsening in the performance of rotarod (Fig. 1C) and hanging-wire (Fig. 1D) tests. Rotarod performance (mean latency to fall over 3 days of training) was already reduced in Mecp2 Het mice aged 7-8 weeks and further reduced in 13-16 and 19-24 weeks old Mecp2 Het mice. Two-way ANOVA showed highly significant effects of age $(F(3,65)=4.928 ; p=0.0038)$, genotype $(F(1,65)=37.75 ; p<$ $0.0001)$ and interaction between age and genotype $(F(3,65)=6.193 ; p=0.0009)$. Hanging-wire performance was impaired in Mecp2 Het mice aged 13-16 and 19-24 weeks, whereas no significant differences were observed between Mecp2 Het and WT mice aged 7-8 weeks. ANOVA showed significant effects of age $(F(3,58)=5.709 ; p=$ 0.0017), genotype $(F(1,58)=32.3 ; p<0.0001)$ and interaction between age and genotype $(F(3,58)=3.105 ; p=0.0334)$.

\subsection{Effect of repeated administration of fluoxetine and citalopram on motor coordination} in Mecp2 Het mice

At the end of the 2-week treatment, a complete rescue of the motor deficit was observed in Mecp2 Het mice receiving $10 \mathrm{mg} / \mathrm{kg}$ fluoxetine daily (Figs. 2A and 2B). 

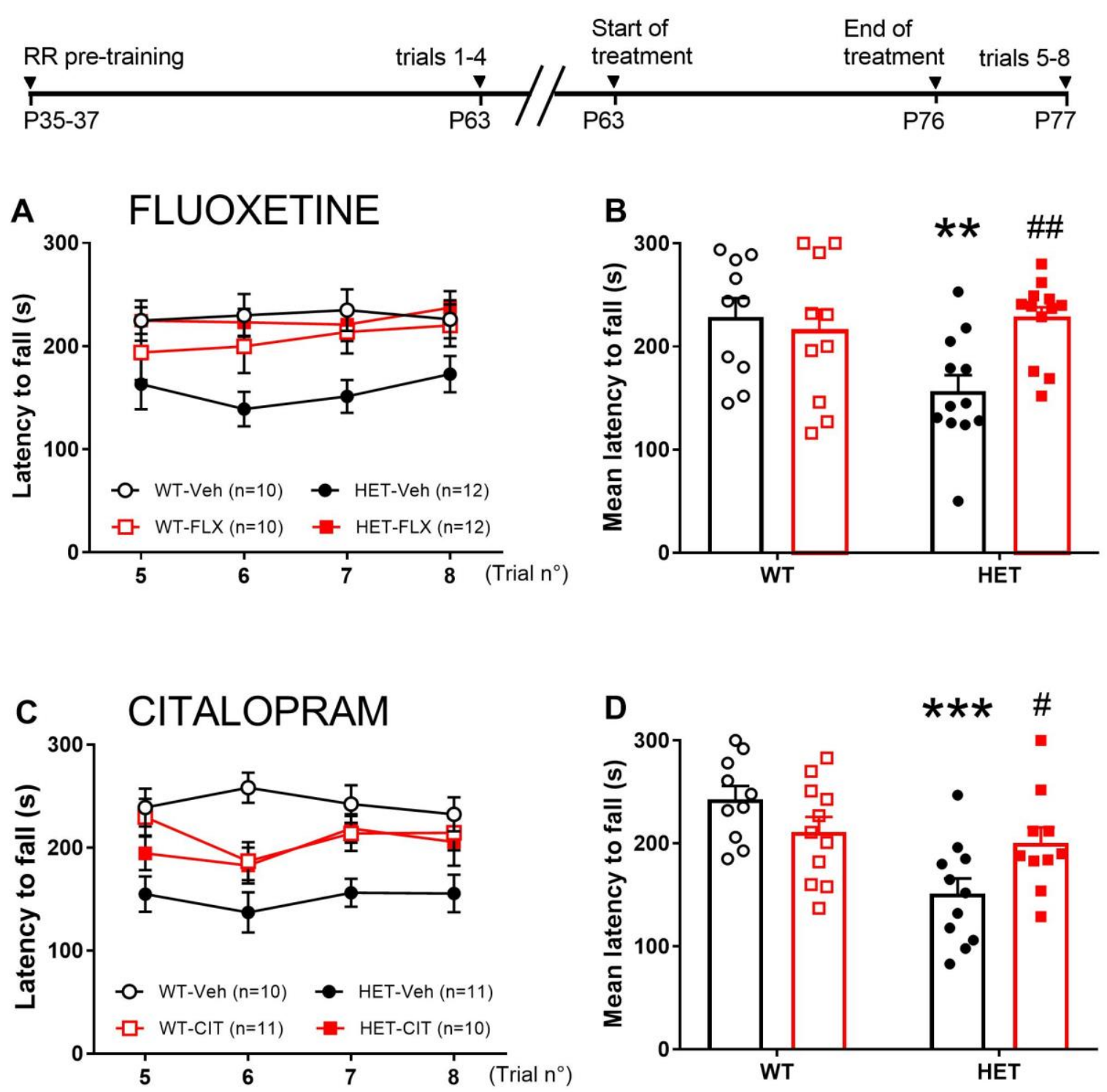

Fig. 2 Effect of 14-day treatment with fluoxetine and citalopram on rotarod performance in Mecp2 Het mice.

Upper panels show the trial by trial (panel A) and the mean latency to fall (panel B) in Mecp2 Het and WT mice treated with vehicle (Veh) or fluoxetine. The same parameters measured in mice receiving citalopram (CIT) in the drinking water are shown in panels $\mathrm{C}$ and $\mathrm{D}$. The horizontal bar on top of the figure shows the schedule of treatment and the timing of behavioral assessment. Data are mean \pm SEM. Symbols and histograms in panels $B$ and $D$ represent individual data points and the mean of the group, respectively. The number of mice per group is shown in parentheses. ${ }^{*} p=0.008$ and ${ }^{* *} p<0.0001$ vs. respective WT-vehicle; $\# p=0.0413$, \#\#p =0.0069 vs. HET-Veh (Sidak's test). RR, rotarod testing; P, postnatal day.

Two-way ANOVA showed a significant interaction between treatment and genotype $(F(1,40)=6.466, p=0.015)$, but not genotype $(F(1,40)=3.164, p=0.083)$ and 
treatment $(F(1,40)=2.726, p=0.107)$. Post-hoc analysis confirmed that Mecp2 Het mice treated with fluoxetine remained significantly longer on the rotarod than those receiving vehicle, reaching a performance similar to that observed in WT mice. Fluoxetine had no significant effects on the latency to fall in WT mice.

Two-week administration of $20 \mathrm{mg} / \mathrm{kg} /$ day citalopram in the drinking water significantly improved rotarod performance in Mecp2 Het mice (Figs. 2C and 2D). Two-way ANOVA showed a significant interaction between treatment and genotype $(F(1,38)=7.864, p$ $=0.0079)$, genotype $(F(1,38)=12.6, p=0.001)$ but not treatment $(F(1,38)=0.3655, p$ $=0.549)$.

The number of slips in the beam walking test was higher in Mecp2 Het than in WT mice and fluoxetine significantly reduced them (Fig. $3 A$; treatment $F(1,32)=5.039, p=$ 0.0318; genotype $F(1,32)=39.74, p<0.00001$; and interaction between genotype and treatment $(F(1,32)=5.31, p=0.0278)$. Likewise, citalopram reduced the number of slips in Mecp2 Het mice (Fig. 3B). ANOVA showed a significant effect of treatment (F $(1,38)=8.196, p=0.0068)$, genotype $(F(1,38)=21.42, p<0.0001)$ and their interaction $(F(1,38)=6.37, p=0.0159)$.
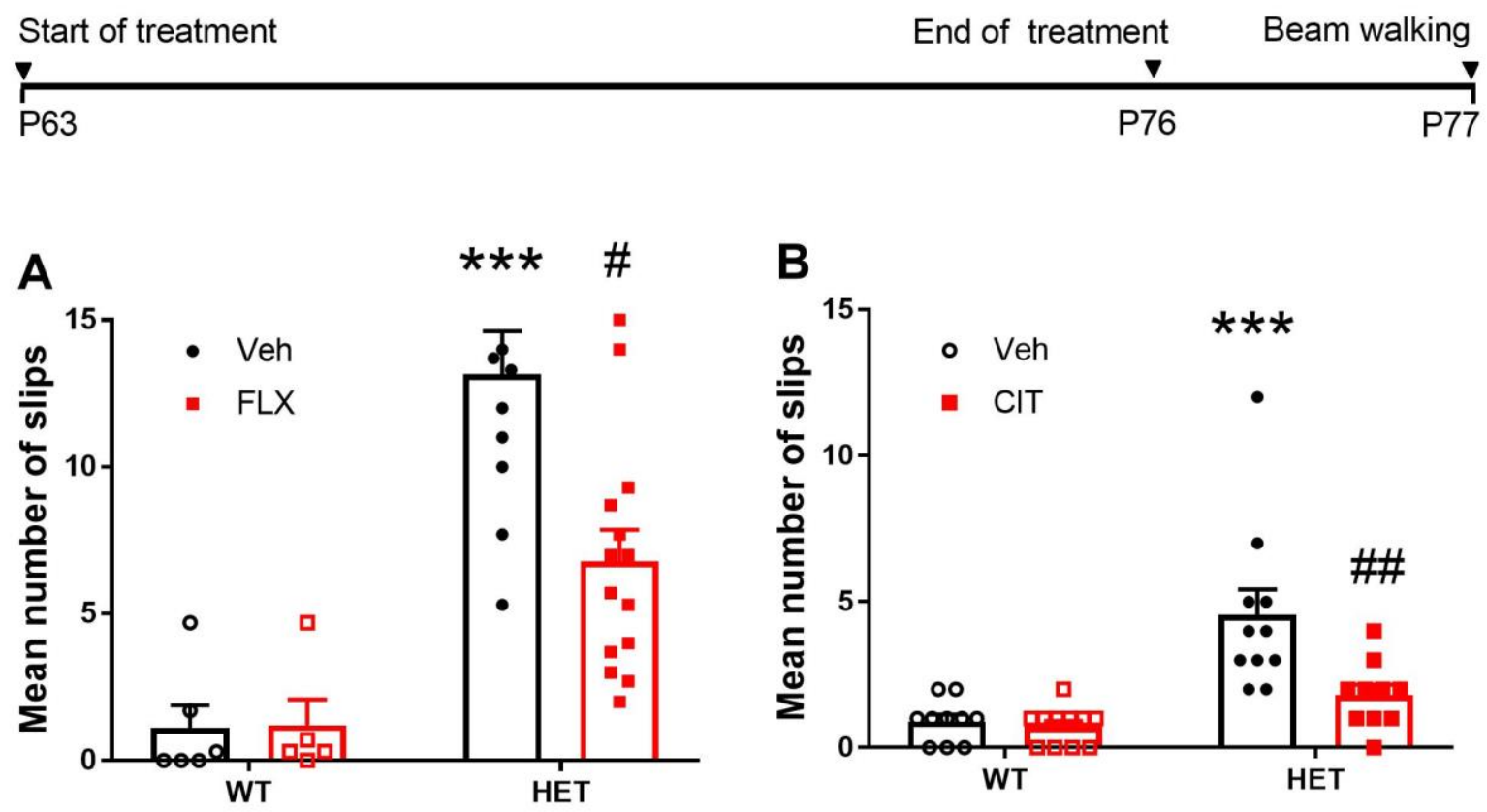
bioRxiv preprint doi: https:/doi.org/10.1101/2020.06.12.147876: this version posted June 12, 2020. The copyright holder for this preprint (which was not certified by peer review) is the author/funder, who has granted bioRxiv a license to display the preprint in perpetuity. It is made available under aCC-BY-NC-ND 4.0 International license.

Fig 3 Effect of fluoxetine and citalopram on beam walking performance in Mecp2 Het and WT mice.

Panels $A$ and $B$ show the effect of fluoxetine and citalopram, respectively. The horizontal bar on top of the figure illustrate the schedule of treatment and the timing of behavioral assessment. Black and red symbols in panels $A$ and $B$ represent individual data points. Histograms are the mean number of slips over 3 consecutive trials \pm SEM of 10-11 mice per group.

${ }^{* * *} p<0.0001$ vs. WT-H ${ }_{2} \mathrm{O} ;{ }^{*} p=0.0016,{ }^{\# \#} p=0.003$ vs. HET-Veh (Sidak's test). BW, beam walking; $P$, postnatal day.

Mecp2 Het mice showed a reduced score in the hanging-wire test as compared to WT mice (WT/Vehicle $8.6 \pm 0.7, n=11$ Mecp2 Het/vehicle $4.9 \pm 0.8, n=16 ; p<0.0001$ Dunn's test). Two-week treatment with fluoxetine did not significantly improve the ability of Mecp2 Het mice to perform the test (WT/fluoxetine $9.1 \pm 0.5, n=10$, Mecp2 Het/fluoxetine $5.3 \pm 0.8, n=16 ; p<0.01$, Dunn's test; data not shown).
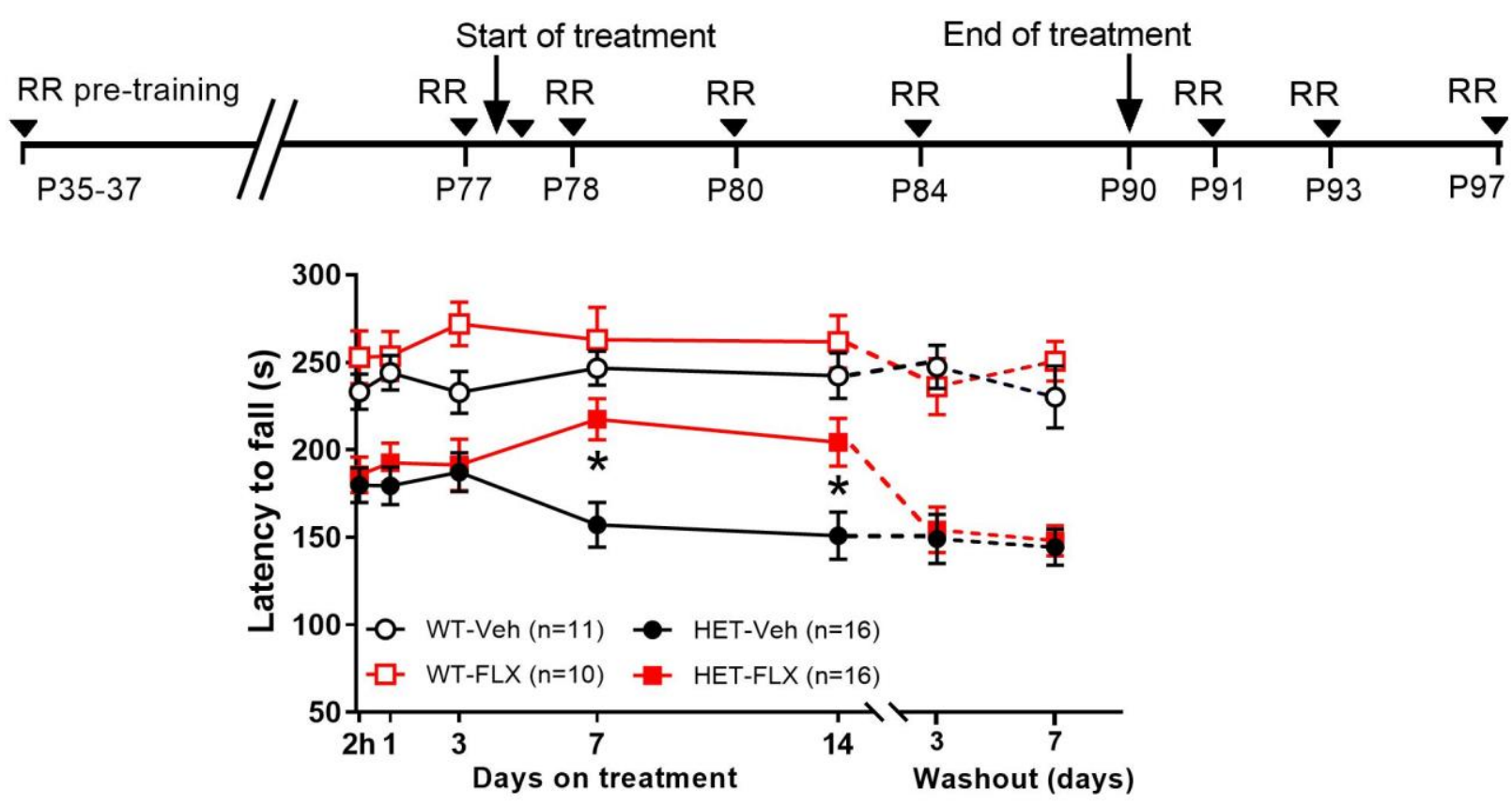

Fig. 4 Onset and duration of fluoxetine effect in the rotarod in Mecp2 Het and wild type mice.

Mice received $10 \mathrm{mg} / \mathrm{kg}$ IP fluoxetine (FLX) or vehicle $\left(\mathrm{H}_{2} \mathrm{O}\right)$ daily and were repeatedly exposed to rotarod during treatment and after treatment suspension as indicated by arrowheads in the timeline above the graph. Except for the first time point, mice were exposed to rotarod $24 \mathrm{~h}$ after the last dose. Each time-point is the mean \pm SEM of 4 daily trials. The number of mice per group is shown in parentheses. Asterisks indicate $\mathrm{p}<0.05$ vs. HET-Veh (Sidak's test). RR, rotarod testing; $\mathrm{P}$, postnatal day 
Fig. 4 shows the onset of fluoxetine effect on the rotarod and 3 and 7 days after drug suspension. ANOVA showed a highly significant interaction between genotype, treatment and days on treatment $(F(4,196)=4.786, p=0.0011)$. Further analysis at each time point showed that fluoxetine prolonged the latency to fall in Mecp2 Het mice after $7(F(1,49)=8.002, p=0.0068)$ and $14(F(1,49)=6.438, p=0.0144)$ days but had no effect after $2 \mathrm{~h}, 24 \mathrm{~h}$ and 3 days of treatment in Mecp2 Het mice and at any times after administration in WT mice. In Mecp2 Het mice, the effect of fluoxetine disappeared 3 days after drug suspension.

\subsection{Inhibition of 5-HT synthesis prevents fluoxetine ability to rescue rotarod deficit}

Mecp2 Het mice receiving $10 \mathrm{mg} / \mathrm{kg}$ fluoxetine for 14 days showed an improved response in the rotarod as compared to those receiving vehicle and pCPA abolished the effect of fluoxetine (Fig. 5). ANOVA showed a significant effect of fluoxetine $(F(1,40)=13.98, p=0.0006), p C P A(F(1,40)=7.037, p=0.0114)$ and interaction between fluoxetine and $\mathrm{pCPA}(F(1,40)=8.103, \mathrm{p}=0.0069)$.
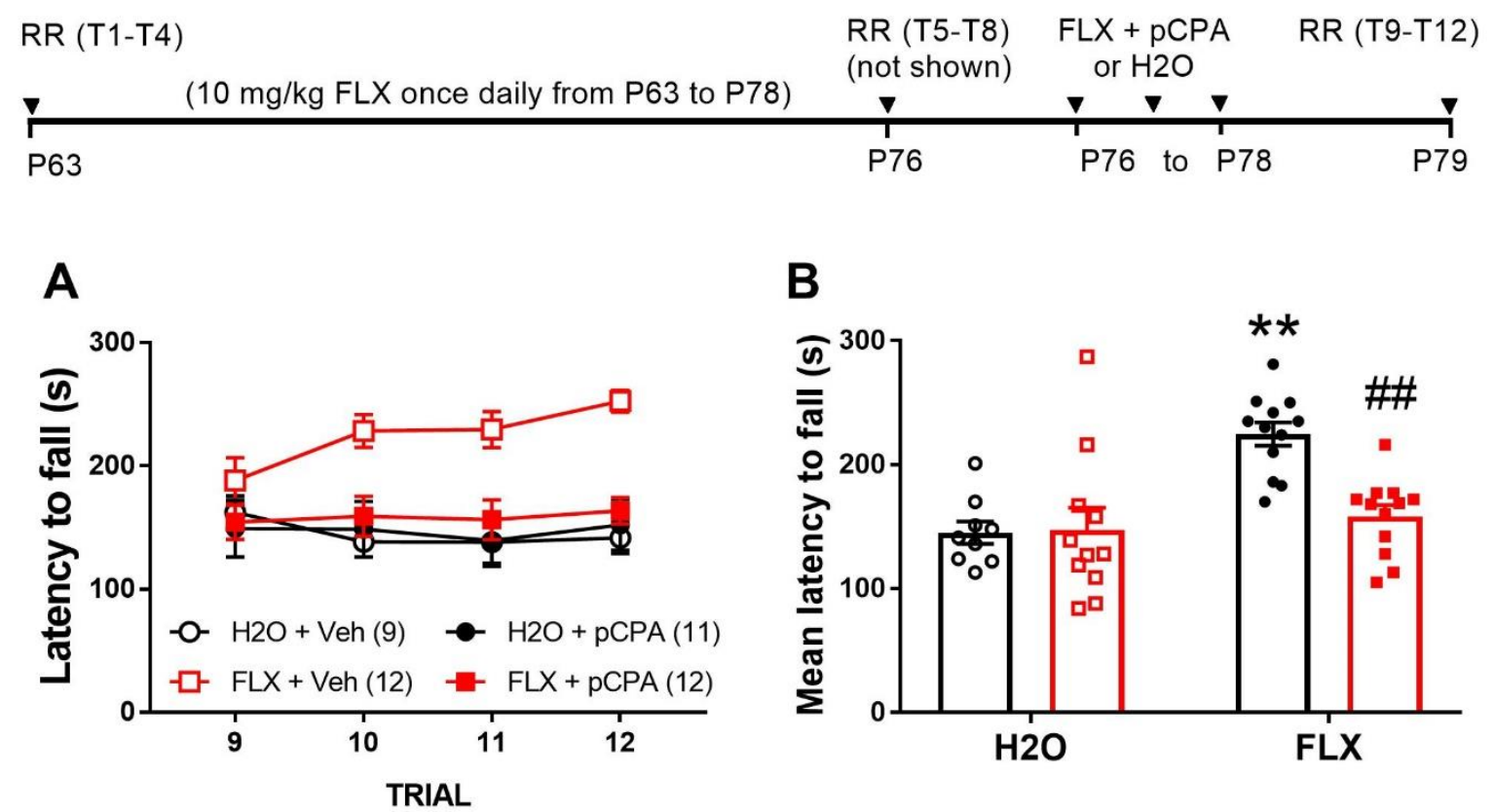
bioRxiv preprint doi: https:/doi.org/10.1101/2020.06.12 147876: this version posted June 12, 2020. The copyright holder for this preprint (which was not certified by peer review) is the author/funder, who has granted bioRxiv a license to display the preprint in perpetuity. It is made available under aCC-BY-NC-ND 4.0 International license.

Fig. 5 Effect of the 5-HT synthesis inhibitor pCPA on fluoxetine-induced improvement of rotarod performance in Mecp2 Het mice

Panel A show the single trial performance after the administration of fluoxetine alone or fluoxetine + pCPA in Mecp2 Het mice given repeated dosing of fluoxetine or water. The mean of the 4 daily trials are shown on the right panels. The horizontal bar on top of the figure illustrate the schedule of treatment and timing of behavioral assessment. $P$, postnatal day; $R R$, rotarod. Black and red symbols in panel $B$ represent individual data points. Symbols in panel $A$ and histograms in panel $B$ are the mean \pm SEM. The number of mice per group is shown in parentheses. ${ }^{* *} \mathrm{p}=0.0003$ vs. $\mathrm{H}_{2} \mathrm{O}-\mathrm{Veh},{ }^{\#} \mathrm{p}=$ 0.0011 vs. FLX-Veh (Sidak's test).

pCPA had no significant effect on rotarod performance in Mecp2 Het mice treated with vehicle and in WT mice (data not shown).

\subsection{Effects of fluoxetine on rotarod deficit in male Mecp2 null mice}

Mecp2 null mice show severe rotarod deficits already at P35 causing about 50\% reduction in the latency to fall as compared to WT mice (Fig. 6). Daily injections of 10 $\mathrm{mg} / \mathrm{kg}$ fluoxetine for two weeks slightly but significantly increased the latency to fall in Mecp2 null mice as compared to those receiving vehicle.
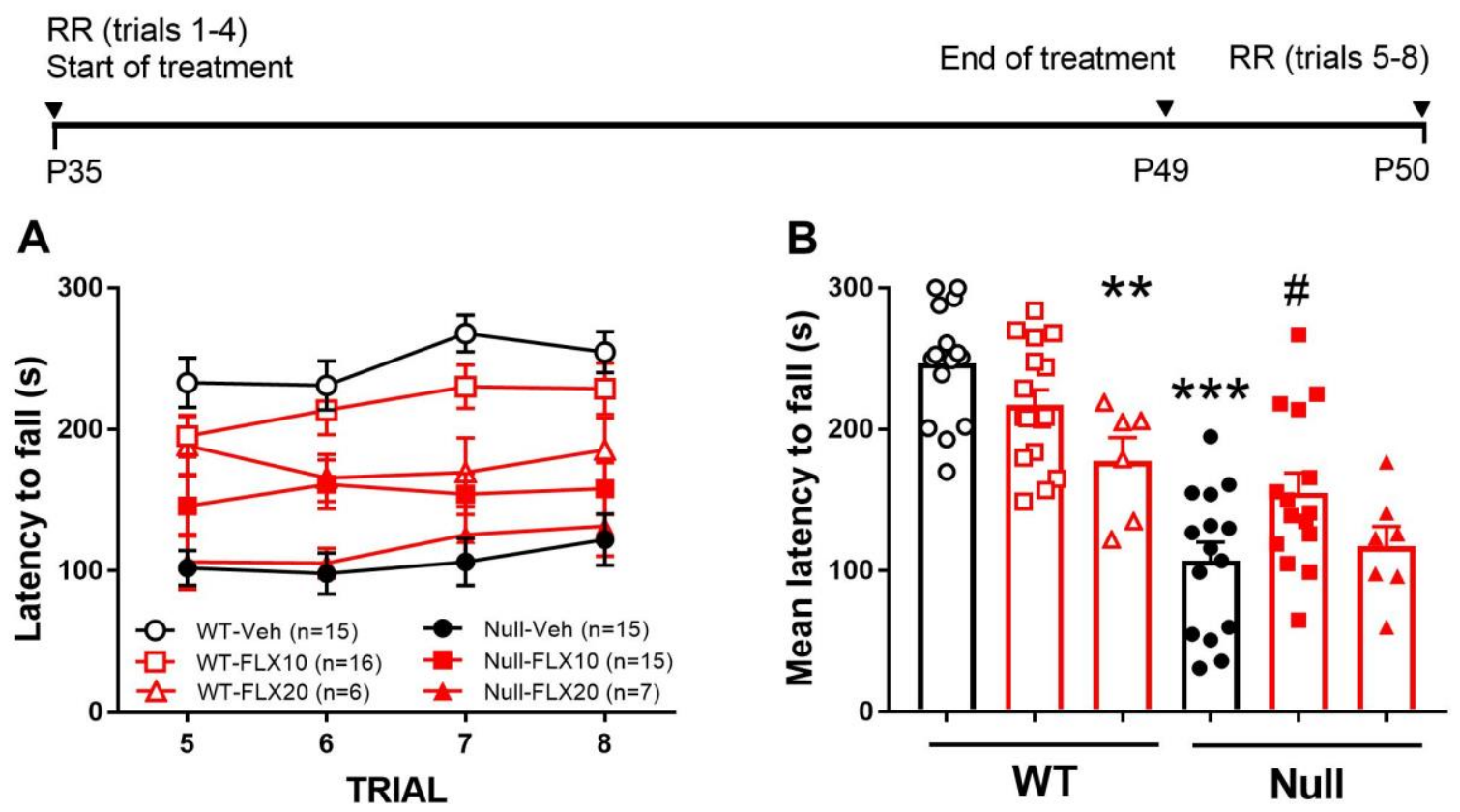

Fig. 6 Rotarod performance in Mecp2 null (Null) and wild type (WT) mice treated with 10 and $20 \mathrm{mg} / \mathrm{kg}$ fluoxetine (FLX) or vehicle (Veh) for 14 days.

The latency to fall for each trial and the mean latency to fall of 4 daily trials are shown in panels $A$ and $B$, respectively. The horizontal bar on top of the figure illustrate the schedule of treatment and timing of behavioral assessment. Symbols and histograms in panel B represent individual data points and the mean of the group, respectively. 
Symbols in panel $A$ are the mean \pm SEM. The number of mice per group is shown in parentheses. P, postnatal day; $R R$, rotarod. ${ }^{* *} p=0.0082,{ }^{* * *} p<0.0001$ vs. WT-Veh; $\# p=0.018$ vs. Null-Veh (Sidak's test).

Increasing the dose of fluoxetine to $20 \mathrm{mg} / \mathrm{kg}$ had no effect in Mecp2 null mice, but significantly reduced rotarod performance in WT mice. ANOVA showed a significant effect of treatment $(F(2,68)=3.227, p=0.0458)$, genotype $(F(1,68)=56.59, p<$ $0.0001)$ and interaction between genotype and treatment $(F(2,68)=6.372, p=0.0029)$.

\subsection{5-HT synthesis}

Table1 shows the accumulation of 5-HTP after aromatic aminoacid decarboxylase inhibition, an in vivo indicator of $5-\mathrm{HT}$ synthesis, in various brain regions of male and female Mecp2 mutants and WT mice. A significant reduction of 5-HTP levels by 31, 25 and $15 \%$ was found in the PFC, HIP and STR of Mecp2-null mice, respectively. No significant changes were observed in the BST and RCx. No significant differences in 5-HTP levels were observed between female Mecp2 Het and WT mice in any of the brain regions examined.

Table 1 Accumulation of 5-HTP in various brain regions of Mecp2-null, Mecp2 Het and respective WT mice.

\section{$\begin{array}{llll}\text { WT } & \text { Mecp2-null } & \text { WT } & \text { Mecp2-Het }\end{array}$}

5-HTP $\mathrm{ng} / \mathrm{g}$ tissue $(\mathrm{n})$

$\begin{array}{lllll}\text { Prefrontal cortex } & 168 \pm 18(6) & \mathbf{1 1 6} \pm \mathbf{1 4}^{\mathrm{a}}(6) & 186 \pm 10(6) & 163 \pm 14(6) \\ \text { Hippocampus } & 352 \pm 15(7) & \mathbf{2 6 3} \pm \mathbf{1 2}(6) & 372 \pm 21(6) & 353 \pm 46(6) \\ \text { Striatum } & 283 \pm 15(7) & \mathbf{2 4 0} \pm \mathbf{7}^{\mathrm{c}}(6) & 207 \pm 11(6) & 233 \pm 29(6) \\ \text { Brainstem } & 461 \pm 36(7) & 391 \pm 28(6) & 506 \pm 23(6) & 531 \pm 39(6) \\ \text { Remaining Cortex } & 199 \pm 16(7) & 168 \pm 7(6) & 211 \pm 8(6) & 199 \pm 9(6)\end{array}$

Data are mean \pm SEM. Significant differences are indicated in bold-type. ${ }^{\mathrm{a}} \mathrm{p}=0.0415,{ }^{\mathrm{b}} \mathrm{p}=$ $0.0008 ;{ }^{c} p=0.0309$ (Student's t-test) 


\subsection{Effect of fluoxetine on extracellular 5-HT in the PFC}

Fig. 7 shows basal extracellular 5-HT in the PFC of WT (panel A) and Mecp2 mutant (panel B) treated with vehicle or fluoxetine for 6 days. Twenty-four $h$ after the last dose extracellular 5-HT was significantly higher in WT mice receiving fluoxetine as compared to those treated with vehicle. No differences in 5-HT levels were observed between sexes either in mice given vehicle or fluoxetine. Likewise, no differences in extracellular 5-HT were found between Mecp2 Het and Mecp2 null mice receiving repeated doses of vehicle. ANOVA showed a highly significant effect of treatment $(F(1,14)=82.97 ; p<0.0001)$ but not $\operatorname{sex}(F(1,14)=0.0223 ; p=0.883)$ and interaction between treatment and $\operatorname{sex}(F(1,14)=0.185 ; p=0.674)$. Repeated treatment with fluoxetine significantly increased extracellular 5-HT in Mecp2 Het mice, reaching levels similar to those observed in WT mice receiving the same treatment, whereas fluoxetine had much less effect in Mecp2 null mice (panel B). ANOVA showed a significant effect of treatment $(F(1,18)=22.21 ; p=0.0002)$ and $\operatorname{sex}(F(1,18)=6.412 ; p=0.0209)$ but not interaction between these factors $(F(1,18)=2.915 ; p=0.105)$.

After an acute fluoxetine challenge, mice repeatedly treated with vehicle show a significant increase of extracellular 5-HT, regardless their genotype and sex (panel C). ANOVA showed significant effects of time $(F(1,17)=17.127 ; p<0.0001)$ but not sex $(F 1,17)=0.280 ; p=0.604)$, genotype $(F(1,17)=1.493 ; p=0.239)$ and interaction between genotype and $\operatorname{sex}(F(1,17)=0.257 ; p=0.619)$. In mice repeatedly treated with fluoxetine, no further increase was observed upon the administration of the acute challenge in WT and mutant mice of both sexes. Extracellular 5-HT in Mecp2 null mice remained significantly lower than in WT and Mecp2 Het mice over the entire observation period (panel D). ANOVA showed significant effects of $\operatorname{sex}(F(1,15)=$ 5.023; $p<0.041)$, time $(F(12,180)=3.703 ; p<0.0001)$, but not genotype $(F(1,15)=$ 
bioRxiv preprint doi: https:/doi.org/10.1101/2020.06.12.147876: this version posted June 12, 2020. The copyright holder for this preprint (which was not certified by peer review) is the author/funder, who has granted bioRxiv a license to display the preprint in perpetuity. It is made available under aCC-BY-NC-ND 4.0 International license.

$2.544 ; p=0.132)$ and interaction between genotype and $\operatorname{sex}(F(1,15)=2.186 ; p=$ $0.160)$.

\begin{tabular}{lll} 
Start of treatment & $\begin{array}{l}\text { Surgery } \\
\text { End of treatment }\end{array}$ & $\begin{array}{l}\text { Basal samples } \\
\text { FLX challenge }\end{array}$ \\
\hline P42 (males) & P48 (males) & P49 (males) \\
P63 (females) & P69 (females) & P70 (females)
\end{tabular}

A

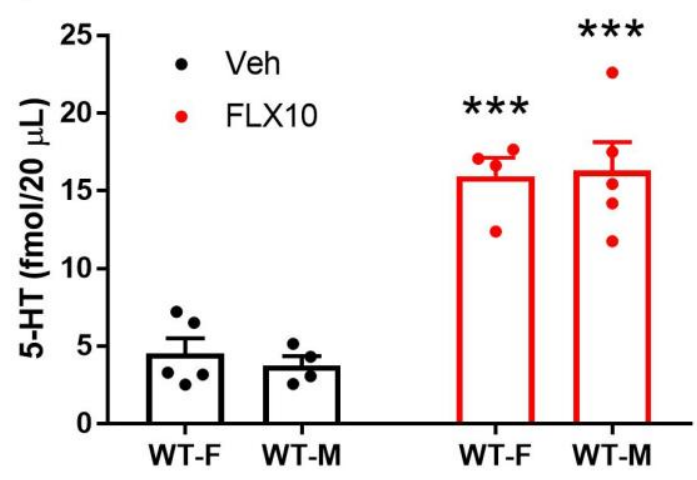

C

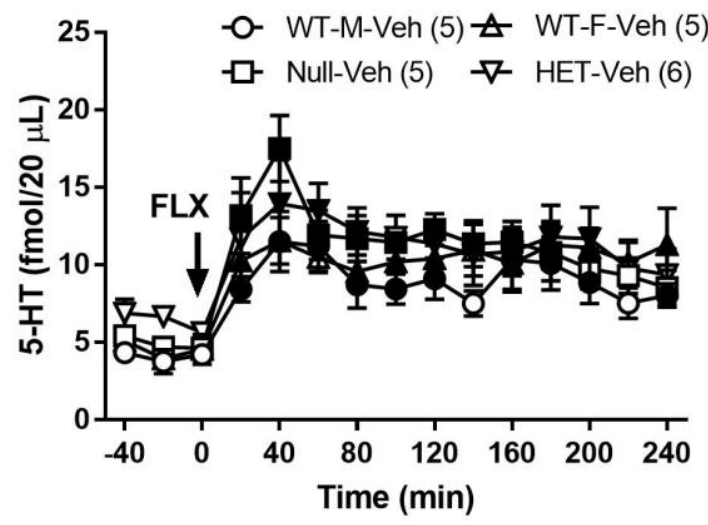

B

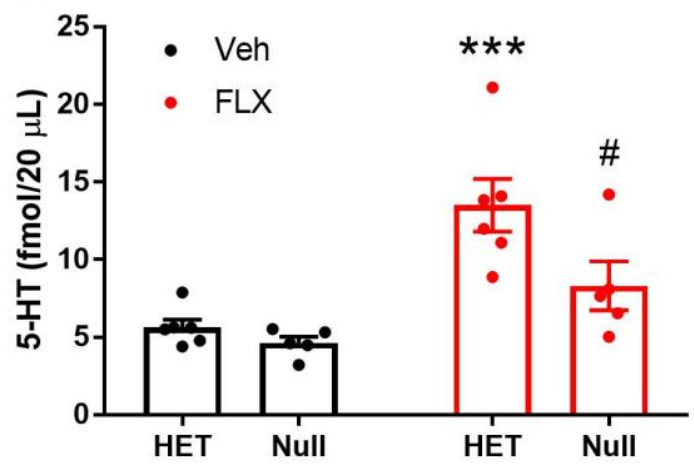

D

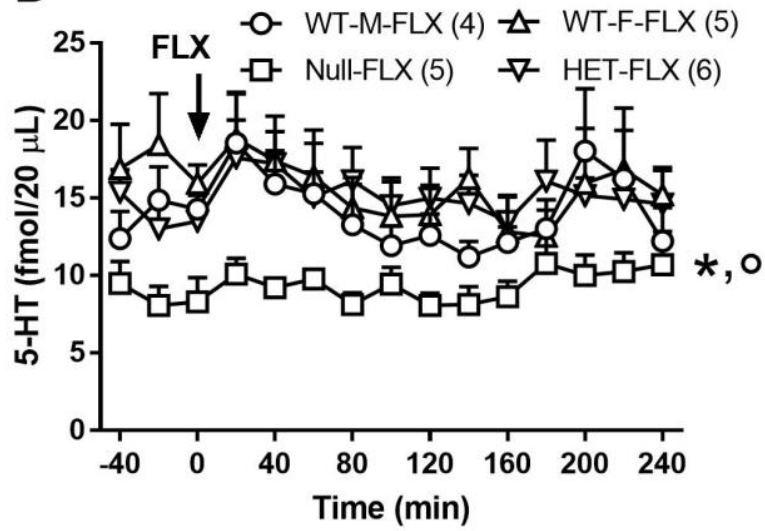

Fig. 7 Effect of repeated treatment with fluoxetine on extracellular 5-HT in the PFC. Basal extracellular levels of 5-HT in the PFC of WT male (WT-M) and female (WT-F) mice (panel A), and Mecp2 Het (HET) female and Mecp2-null (Null) male mice (panel B). 5-HT was measured $24 \mathrm{~h}$ after 6 days treatment with vehicle (Veh) or fluoxetine (FLX). Dots in panels A and B represent individual data points. ${ }^{* * *} p<0.0001$ vs. respective vehicle; $\# p=0.0032$ vs. Het-FLX (Sidak's test).

Lower panels show he effects of a challenge dose of fluoxetine administered $24 \mathrm{~h}$ after the last dose of vehicle (Veh; panel C) or fluoxetine (FLX; panel D) in WT and Mecp2mutant mice of both sexes. Histograms in panels $A$ and $B$ and symbols in panels $C$ and $D$ are mean \pm SEM. The number of mice/group is shown in parentheses. Solid symbols in panel $C$ indicate $p<0.05$ vs. pre-injection (basal) values. ${ }^{*} p<0.05$ between Null-FLX and WT-M- $\mathrm{H}_{2} \mathrm{O} ;{ }^{\circ} p<0.05$ between Null-FLX and HET-FLX (Tukey's test). 
bioRxiv preprint doi: https:/doi.org/10.1101/2020.06.12.147876; this version posted June 12, 2020. The copyright holder for this preprint (which was not certified by peer review) is the author/funder, who has granted bioRxiv a license to display the preprint in perpetuity. It is made available under aCC-BY-NC-ND 4.0 International license.

\subsection{Effects of fluoxetine on 8-OH-DPAT-induced hypothermia}

8-OH-DPAT reduced core temperature, reaching $-1.7^{\circ} \mathrm{C}$ in $\mathrm{WT}$ male and $-1.9^{\circ} \mathrm{C}$ in WT female mice. 8-OH-DPAT had similar effect in Mecp2 null mice $\left(-1.6^{\circ} \mathrm{C}\right)$, whereas the drop in temperature was significantly greater in Mecp2 Het mice $\left(-2.6^{\circ} \mathrm{C}\right.$; Fig. 8). The hypothermic effect induced by 8-OH-DPAT was markedly attenuated by fluoxetine in male and female mice of both genotypes. In male mice, ANOVA showed significant effects of treatment $(F(1,21)=4.989 ; p=0.037)$ but not genotype $(F(1,21)$ $=0.023 ; p=0.882)$, and interaction between genotype and treatment $(F(1,21)=$ $0.065 ; p=0.801)$. In female mice, ANOVA showed significant effects of genotype $(F(1,21)=7.498 ; p=0.0123)$, treatment $(F(1,21)=61.41 ; p<0.0001)$ but not interaction between genotype and treatment $(F(1,21)=1.043 p=0.319)$.
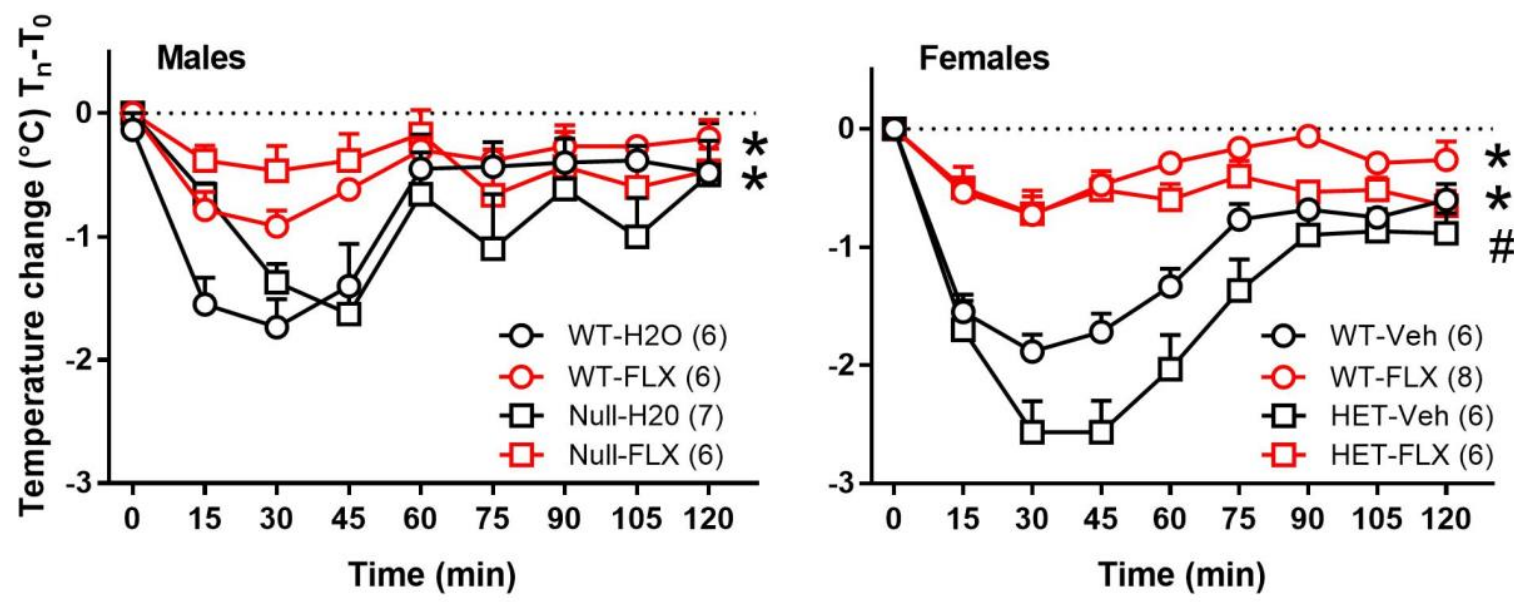

Fig. 8 Effect of 6 days treatment with fluoxetine (FLX) or vehicle (Veh) on 8-OH-DPATinduced hypothermia.

Male Mecp2-null (Null) and WT mice and female Mecp2-Het (HET) and WT mice were injected with $8-\mathrm{OH}-\mathrm{DPAT}$ at $\mathrm{t}=0 \mathrm{~min}$. Core temperature was measured immediately before 8-OH-DPAT injection and every 15 min thereafter. Data are expressed as mean \pm SEM of the difference between temperature measured at each time after 8-OH-DPAT injection and basal values $\left(\mathrm{T}_{0}\right)$. Basal temperature $\left({ }^{\circ} \mathrm{C}\right)$ measured $24 \mathrm{~h}$ after the repeated administration of fluoxetine or vehicle for 6 days was: males, WT-Veh $38.2 \pm$ 0.2, WT-FLX $38.3 \pm 0.1$, Mecp2 null-Veh $37.7 \pm 0.2$ and Mecp2 null-FLX $38.0 \pm 0.3$; females, WT-Veh $38.2 \pm 0.1$, WT-FLX $38.1 \pm 0.1$, Mecp2 Het-Veh $38.0 \pm 0.1$ and Mecp2 Het-FLX $38.3 \pm 0.1$. 
bioRxiv preprint doi: https://doi.org/10.1101/2020.06.12.147876; this version posted June 12, 2020. The copyright holder for this preprint (which was not certified by peer review) is the author/funder, who has granted bioRxiv a license to display the preprint in perpetuity. It is made available under aCC-BY-NC-ND 4.0 International license.

The number of mice/group is shown in parentheses. ${ }^{*} \mathrm{p}<0.05$ between WT-FLX and WT- $\mathrm{H}_{2} \mathrm{O} ;{ }^{\circ} \mathrm{p}<0.05$ between Het/null-FLX and Het/null-Veh; \#p $<0.05$ between HetVeh and WT-Veh (Tukey's test). 


\section{Discussion}

Motor deficits represent one of the most disabling symptoms of RTT. Mecp2 Het mice show an early onset of rotarod deficit (Samaco et al., 2013), worsening over time, which is fully rescued by fluoxetine treatment. The rotarod improvement was larger than commonly found with other molecules tested so far in mouse models of RTT (Braun et al., 2012; Buchovecky et al., 2013; Krishnan et al., 2015; Mellios et al., 2014; Nag and Berger-Sweeney, 2007) and comparable to that observed after genetic rescue of Mecp2 gene (Chao et al., 2010; Garg et al., 2013). The robustness of our findings is supported by the ability of fluoxetine to rescue rotarod deficit in Mecp2 Het mice differing for age, training on the rotarod, severity of motor impairment, and route of drug administration (drinking water; Fig. S2). The ability of fluoxetine to rescue the coordination deficit was confirmed in the beam walking task, that similarly to rotarod assesses motor coordination and balance (Carter et al., 2001). Likewise, citalopram rescued rotarod and beam walking deficits. Although the number of slips of Mecp2 Het mice used to assess the effect of fluoxetine was larger than in the experiment with citalopram, these differences apparently had no consequences on drugs' ability to counteract beam walking deficit. Previous studies showed that i.p. injection, the route used for fluoxetine administration, increased corticosterone secretion and influenced neuronal activity and mouse behavior (Cabib et al., 1990; Ryabinin et al., 1999; Sousa et al., 2006; Stuart and Robinson, 2015). Thus, the different number of slips showed by Mecp2 Het mice across experiments, is likely related to the stress caused by the i.p. injection, which depending on mouse genetic background may adapt or not to repeated injections (Ryabinin et al., 1999). Fluoxetine failed to improve performance in the hanging-wire test. As muscle strength is required to oppose the effect of gravity in the hanging-wire but not in the rotarod and beam walking tests, it is conceivable that fluoxetine mainly affects motor 
coordination and balance rather than muscle strength (Klein et al., 2012; Osmon et al., 2018). Further assessment using other tests, such as grip strength, are needed to support this interpretation. However, it cannot be excluded that extending treatment duration by more than 2 weeks or starting fluoxetine administration before symptom onset may improve the hanging-wire performance.

We found that 5-HT synthesis inhibition abolished the rotarod improvement induced by fluoxetine in Mecp2 Het mice indicating a major role of 5-HT in this effect. The fact that citalopram, another SSRI with a different chemical structure, shared the ability of fluoxetine to rescue motor deficits in the rotarod and beam walking tests further supports the importance of $5-\mathrm{HT}$ in the mechanisms by which these drugs improve motor coordination. The dose of pCPA used in the current study reduced 5-HTP accumulation by $50-75 \%$ and prevented the antidepressant-like effect of citalopram and paroxetine in the forced swimming test (Cervo et al., 2005; Guzzetti et al., 2008). In addition, polymorphism of the Tph2 gene, which reduces brain 5-HT synthesis by $25-40 \%$, was sufficient to prevent the antidepressant-like effect of SSRIs (Cervo et al., 2005; Guzzetti et al., 2008). These findings are consistent with previous studies showing that SSRIs enhance motor skill learning and plasticity likely by enhancing synaptic availability of brain 5-HT, which is known to regulate motor networks and facilitate motor skill (Batsikadze et al., 2013; Gerdelat-Mas et al., 2005; Loubinoux et al., 2005).

We found that fluoxetine was poorly effective in contrasting rotarod deficits in male Mecp2 null mice. Interestingly, we found reduced 5-HT synthesis in the PFC, HIP and STR of male Mecp2-null mice, while no changes are found in no brain region of Mecp2 Het mice. These findings are consistent with data showing reduced $5-\mathrm{HT}$ levels, and Tph2 gene expression and protein in the raphe and other brain regions of Mecp2 null mice and in post-mortem brain samples of RTT patients (Ide et al., 2005; 
Panayotis et al., 2011; Samaco et al., 2009; Santos et al., 2010; Vogelgesang et al., 2017). Except for a study showing reduced levels of 5-HT in the raphe region but not in the hippocampus (Isoda et al., 2010), evidence for brain 5-HT alterations in Mecp2deficient female mice are lacking. In all the brain areas examined for changes in 5HTP accumulation, tryptophan levels were similar between Mecp2 null and WT mice (Table S1). Thus, we can exclude that insufficient supply of 5-HT precursor TRP from diet may account for reduced 5-HT synthesis (Fernstrom, 1983). Neurodegeneration of $5-\mathrm{HT}$ neurons is also excluded as no differences in the number of brain $5-\mathrm{HT}$ neurons have been observed between Mecp2-null and WT mice (Santos et al., 2010). Thus, the most parsimonious explanation for reduced 5-HT synthesis in Mecp2 null mice is a cell autonomous mechanism exerted through the direct control of Tph2 expression by the Mecp2 gene Samaco et al., 2009).

Differences in brain and plasma levels of fluoxetine, as well as differences in norfluoxetine to fluoxetine ratio have been found between male and female mice (Hodes et al., 2010). In agreement, we found lower brain and plasma levels of norfluoxetine in Mecp2-null mice as compared to mutant females (Table S2). However, doubling the dose of fluoxetine failed to improve rotarod performance in Mecp2-null mice despite plasma and brain fluoxetine and norfluoxetine reached levels similar or higher than those found in females receiving $10 \mathrm{mg} / \mathrm{kg}$ fluoxetine (Table S2). Thus, the poor effect of fluoxetine in male Mecp2-null mice is not attributable to low exposure to the drug or its metabolite. It is unlikely that increasing further fluoxetine dose would improve its efficacy in male mice as reduced rotarod performance is observed in mice receiving $20 \mathrm{mg} / \mathrm{kg}$ fluoxetine (present study; Fernández-Guasti et al., 2017; Morelli et al., 2011).

The motor effect of fluoxetine was no more present 3 days after drug suspension. This indicates that sufficient amounts of fluoxetine and its active metabolite should be 
present in the brain to support the effect of fluoxetine. The half-life of fluoxetine and nor-fluoxetine in the mouse plasma (about 6 and $12 \mathrm{~h}$, respectively) and the timedependent binding of the drug to the 5-HT transporter are consistent with this interpretation (Hirano et al., 2005).

Fluoxetine administration for at least 6 days is required to achieve a significant rescue of rotarod deficit. The effect is maintained during 2 weeks of administration but is not achieved by a single dose or administration for 3 consecutive days. Likewise, 1-week administration of fluoxetine, a condition sufficient to achieve steady-state levels of brain and circulating fluoxetine (Miller et al., 2008), enhanced extracellular 5-HT in the PFC of Mecp2 Het significantly more than in Mecp2-null mice. On the contrary, neither basal 5-HT release nor the effect of a single dose fluoxetine on extracellular 5-HT is affected by sex and genotype. Consistently, SERT expression in the PFC, motor cortex and brainstem is not affected by Mecp2 gene deletion (Santos et al., 2009; Vogelgesang et al., 2017). However, reduced expression of SERT was found in the hippocampus (Vogelgesang et al., 2017). Thus, it cannot be excluded that basal and fluoxetine-induced enhancement of extracellular 5-HT may be affected in extracortical regions of Mecp2 mutant mice. The development of adaptive mechanisms in response to prolonged fluoxetine administration is responsible for the delayed effect of SSRIs in enhancing the availability of extracellular 5-HT in the PFC and striatum. This occurs mainly through the down-regulation of $5-\mathrm{HT}_{1 \mathrm{~A}}$ autoreceptors-mediated autoinhibitory feedback (Chaput et al., 1991; Fritze et al., 2017; Hensler, 2002; Invernizzi et al., 1996). These prompted us to assess whether sex-dependent adaptation of $5-\mathrm{HT}_{1 \mathrm{~A}}$ autoreceptors sensitivity may account for the inability of fluoxetine to restore rotarod performance in Mecp2 null mice. To address this point, we assessed the hypothermic effect of $8-\mathrm{OH}-\mathrm{DPAT}$, a red-out of $5-\mathrm{HT}_{1 \mathrm{~A}}$ autoreceptors sensitivity (Goodwin et al., 1985). We found that fluoxetine 
desensitized 5- $\mathrm{HT}_{1 \mathrm{~A}}$ autoreceptors to a similar extent in Mecp2 null and Mecp2 Het mice. Thus, the reduced efficacy of fluoxetine on motor coordination and extracellular 5-HT in Mecp2 null mice is not attributable to sexually dimorphic changes in $5-\mathrm{HT}_{1 \mathrm{~A}}$ autoreceptors sensitivity. However, we found that the hypothermic effect of $8-\mathrm{OH}$ DPAT was potentiated in Mecp2 Het, but not in Mecp2 null mice. Enhanced sensitivity to the hypothermic effect of 8-OH-DPAT were also observed in male mice selectively lacking the Mecp2 gene in brain serotonergic neurons (Philippe et al., 2018). These mice showed increased expression, binding and immunoreactivity of $5-\mathrm{HT}_{1 \mathrm{~A}}$ autoreceptors in the raphe nuclei and sex-dependent alteration of emotional behavior (Philippe et al., 2018). These findings suggest that increased expression of $5-\mathrm{HT}_{1 \mathrm{~A}}$ autoreceptors may also underlie the enhanced sensitivity to the hypothermic effect of 8-OH-DPAT in Mecp2 Het mice. Increased expression and sensitivity of 5-HT1A autoreceptors, may result in autonomic dysregulation of respiratory and cardiac rhythms (Audero et al., 2008; Corcoran et al., 2013), which are prominent and lifethreatening symptoms affecting nearly $100 \%$ of subject with RTT over the lifespan (Tarquinio et al., 2018). Thus, fluoxetine may help counteract respiratory deficits of RTT by desensitizing 5- $\mathrm{HT}_{1 \mathrm{~A}}$ autoreceptors. Consistently, breathing irregularities in a girl with RTT were reduced by fluoxetine (Gokben et al., 2012).

\section{Conclusions}

The present study provides robust evidences showing that fluoxetine and citalopram rescue motor coordination deficits in Mecp2 Het mice and that brain 5-HT is necessary for these effects. These findings suggest that fluoxetine and potentially

other SSRls and drugs enhancing 5-HT neurotransmission may have beneficial effects on motor and potentially other symptoms of RTT. However, the pleiotropic effects of fluoxetine encompassing 5-HT neurotransmission, neurogenesis, synaptic 
plasticity, expression of neurotrophic factors and facilitation of MeCP2 protein expression, which are all defective in RTT, suggest that in addition to 5-HT other factors may contribute to the effect of fluoxetine on motor coordination (Cassel et al., 2006; Chang et al., 2006; Duman and Monteggia, 2006; Maya Vetencourt et al., 2008, Nag et al., 2013; Santarelli et al., 2003; Stagni et al., 2015; Villani et al., 2018).

Further studies in animal models more closely reflecting the molecular alterations of the Mecp2 gene found in patients with RTT are needed to improve the translational validity of the present findings and provide the basis to assess whether fluoxetine may have any place in the therapy of RTT.

\section{Acknowledgments}

We thank Dr P. Gagliardi for helping with behavioral and biochemical experiments 


\section{Bibliography}

Amir, R.E., Van den Veyver, I.B., Wan, M., Tran, C.Q., Francke, U., Zoghbi, H.Y., 1999. Rett syndrome is caused by mutations in X-linked MECP2, encoding methyl-CpG-binding protein 2. Nat Genet 23, 185-8. https://doi.org/10.1038/13810

Audero, E., Coppi, E., Mlinar, B., Rossetti, T., Caprioli, A., Banchaabouchi, M.A., Corradetti, R., Gross, C., 2008. Sporadic autonomic dysregulation and death associated with excessive serotonin autoinhibition. Science 321, 130-133. https://doi.org/10.1126/science.1157871

Batsikadze, G., Paulus, W., Kuo, M.-F., Nitsche, M.A., 2013. Effect of Serotonin on Paired Associative Stimulation-Induced Plasticity in the Human Motor Cortex. Neuropsychopharmacology 38, 2260-2267. https://doi.org/10.1038/npp.2013.127

Braun, S., Kottwitz, D., Nuber, U.A., 2012. Pharmacological interference with the glucocorticoid system influences symptoms and lifespan in a mouse model of Rett syndrome. Hum. Mol. Genet. 21, 1673-1680. https://doi.org/10.1093/hmg/ddr602

Buchovecky, C.M., Turley, S.D., Brown, H.M., Kyle, S.M., McDonald, J.G., Liu, B., Pieper, A.A., Huang, W., Katz, D.M., Russell, D.W., Shendure, J., Justice, M.J., 2013. A suppressor screen in Mecp2 mutant mice implicates cholesterol metabolism in Rett syndrome. Nat Genet 45, 1013-20. https://doi.org/10.1038/ng.2714

Cabib, S., Algeri, S., Perego, C., Puglisi-Allegra, S., 1990. Behavioral and biochemical changes monitored in two inbred strains of mice during exploration of an unfamiliar environment. Physiol. Behav. 47, 749-753. https://doi.org/10.1016/0031-9384(90)90089-m

Carter, R.J., Morton, J., Dunnett, S.B., 2001. Motor coordination and balance in rodents. Curr. Protoc. Neurosci. Chapter 8, Unit 8.12. https://doi.org/10.1002/0471142301.ns0812s15

Cassel, S., Carouge, D., Gensburger, C., Anglard, P., Burgun, C., Dietrich, J.B., Aunis, D., Zwiller, J., 2006. Fluoxetine and cocaine induce the epigenetic factors MeCP2 and MBD1 in adult rat brain. Mol Pharmacol 70, 487-92. https://doi.org/mol.106.022301 [pii] 10.1124/mol.106.022301

Cervo, L., Canetta, A., Calcagno, E., Burbassi, S., Sacchetti, G., Caccia, S., Fracasso, C., Albani, D., Forloni, G., Invernizzi, R.W., 2005. Genotype-dependent activity of tryptophan hydroxylase-2 determines the response to citalopram in a mouse model of depression. $J$ Neurosci 25, 8165-72. https://doi.org/10.1523/JNEUROSCI.1816-05.2005

Chahrour, M., Zoghbi, H.Y., 2007. The story of Rett syndrome: from clinic to neurobiology. Neuron 56, 422-37. https://doi.org/10.1016/j.neuron.2007.10.001

Chang, Q., Khare, G., Dani, V., Nelson, S., Jaenisch, R., 2006. The disease progression of Mecp2 mutant mice is affected by the level of BDNF expression. Neuron 49, 341-8. https://doi.org/S0896-6273(06)00010-9 [pii] 10.1016/j.neuron.2005.12.027

Chao, H.T., Chen, H., Samaco, R.C., Xue, M., Chahrour, M., Yoo, J., Neul, J.L., Gong, S., Lu, H.C., Heintz, N., Ekker, M., Rubenstein, J.L., Noebels, J.L., Rosenmund, C., Zoghbi, H.Y., 2010. Dysfunction in GABA signalling mediates autism-like stereotypies and Rett syndrome phenotypes. Nature 468, 263-9. https://doi.org/10.1038/nature09582

Chaput, Y., de Montigny, C., Blier, P., 1991. Presynaptic and postsynaptic modifications of the serotonin system by long-term administration of antidepressant treatments. An in vivo electrophysiologic study in the rat. Neuropsychopharmacology 5, 219-29.

Conti, V., Gandaglia, A., Galli, F., Tirone, M., Bellini, E., Campana, L., Kilstrup-Nielsen, C., Rovere-Querini, P., Brunelli, S., Landsberger, N., 2015. MeCP2 Affects Skeletal Muscle Growth and Morphology through Non Cell-Autonomous Mechanisms. PLOS ONE 10, e0130183. https://doi.org/10.1371/journal.pone.0130183 
Corcoran, A.E., Richerson, G.B., Harris, M.B., 2013. Serotonergic mechanisms are necessary for central respiratory chemoresponsiveness in situ. Respir. Physiol. Neurobiol. 186, $214-$ 220. https://doi.org/10.1016/j.resp.2013.02.015

D’Agostino, 1986. Tests for Normal Distribution, in: Goodness-of-Fit Techniques. Marcel Dekker, New York, pp. 367-420.

De Filippis, B., Musto, M., Altabella, L., Romano, E., Canese, R., Laviola, G., 2015. Deficient Purposeful Use of Forepaws in Female Mice Modelling Rett Syndrome. Neural Plast. 2015, 1-13. https://doi.org/10.1155/2015/326184

Duman, R.S., Monteggia, L.M., 2006. A Neurotrophic Model for Stress-Related Mood Disorders. Biol. Psychiatry 59, 1116-1127. https://doi.org/10.1016/j.biopsych.2006.02.013

Fernández-Guasti, A., Olivares-Nazario, M., Reyes, R., Martínez-Mota, L., 2017. Sex and age differences in the antidepressant-like effect of fluoxetine in the forced swim test. Pharmacol. Biochem. Behav. 152, 81-89. https://doi.org/10.1016/j.pbb.2016.01.011

Fernstrom, J.D., 1983. Role of precursor availability in control of monoamine biosynthesis in brain. Physiol. Rev. 63, 484-546. https://doi.org/10.1152/physrev.1983.63.2.484

FitzGerald, P.M., Jankovic, J., Percy, A.K., 1990. Rett syndrome and associated movement disorders. Mov. Disord. Off. J. Mov. Disord. Soc. 5, 195-202. https://doi.org/10.1002/mds.870050303

Franklin, K.B.J., Paxinos, G., 1997. The Mouse Brain in Stereotaxic Coordinates. Academic Press, San Diego.

Fritze, S., Spanagel, R., Noori, H.R., 2017. Adaptive dynamics of the 5-HT systems following chronic administration of selective serotonin reuptake inhibitors: a meta-analysis. J. Neurochem. 142, 747-755. https://doi.org/10.1111/jnc.14114

Garg, S.K., Lioy, D.T., Cheval, H., McGann, J.C., Bissonnette, J.M., Murtha, M.J., Foust, K.D., Kaspar, B.K., Bird, A., Mandel, G., 2013. Systemic delivery of MeCP2 rescues behavioral and cellular deficits in female mouse models of Rett syndrome. J. Neurosci. Off. J. Soc. Neurosci. 33, 13612-13620. https://doi.org/10.1523/JNEUROSCI.1854-13.2013

Gerdelat-Mas, A., Loubinoux, I., Tombari, D., Rascol, O., Chollet, F., Simonetta-Moreau, M., 2005. Chronic administration of selective serotonin reuptake inhibitor (SSRI) paroxetine modulates human motor cortex excitability in healthy subjects. Neurolmage 27, 314-322. https://doi.org/10.1016/j.neuroimage.2005.05.009

Gokben, S., Ardic, U.A., Serdaroglu, G., 2012. Use of buspirone and fluoxetine for breathing problems in Rett syndrome. Pediatr Neurol 46, 192-4. https://doi.org/S08878994(11)00540-6 [pii] 10.1016/j.pediatrneurol.2011.12.003

Goodwin, G.M., De Souza, R.J., Green, A.R., 1985. The pharmacology of the hypothermic response in mice to 8-hydroxy-2-(di-n-propylamino)tetralin (8-OH-DPAT). A model of presynaptic 5-HT1 function. Neuropharmacology 24, 1187-1194.

Guy, J., Gan, J., Selfridge, J., Cobb, S., Bird, A., 2007. Reversal of neurological defects in a mouse model of Rett syndrome. Science 315, 1143-7. https://doi.org/1138389 [pii] 10.1126/science. 1138389

Guzzetti, S., Calcagno, E., Canetta, A., Sacchetti, G., Fracasso, C., Caccia, S., Cervo, L., Invernizzi, R.W., 2008. Strain differences in paroxetine-induced reduction of immobility time in the forced swimming test in mice: Role of serotonin. Eur J Pharmacol 594, 117124. https://doi.org/S0014-2999(08)00769-3 [pii] 10.1016/j.ejphar.2008.07.031

Hagberg, B., Aicardi, J., Dias, K., Ramos, O., 1983. A progressive syndrome of autism, dementia, ataxia, and loss of purposeful hand use in girls: Rett's syndrome: report of 35 cases. Ann. Neurol. 14, 471-479. https://doi.org/10.1002/ana.410140412

Hensler, J.G., 2002. Differential regulation of 5-HT1A receptor-G protein interactions in brain following chronic antidepressant administration. Neuropsychopharmacology 26, 565-73. 
Hirano, K., Kimura, R., Sugimoto, Y., Yamada, J., Uchida, S., Kato, Y., Hashimoto, H., Yamada, S., 2005. Relationship between brain serotonin transporter binding, plasma concentration and behavioural effect of selective serotonin reuptake inhibitors. Br. J. Pharmacol. 144, 695-702. https://doi.org/10.1038/sj.bjp.0706108

Hodes, G.E., Hill-Smith, T.E., Suckow, R.F., Cooper, T.B., Lucki, I., 2010. Sex-specific effects of chronic fluoxetine treatment on neuroplasticity and pharmacokinetics in mice. J Pharmacol Exp Ther 332, 266-73. https://doi.org/jpet.109.158717 [pii] 10.1124/jpet.109.158717

Ide, S., Itoh, M., Goto, Y., 2005. Defect in normal developmental increase of the brain biogenic amine concentrations in the mecp2-null mouse. Neurosci. Lett. 386, 14-17. https://doi.org/10.1016/j.neulet.2005.05.056

Invernizzi, R., Bramante, M., Samanin, R., 1996. Role of 5-HT1A receptors in the effects of acute chronic fluoxetine on extracellular serotonin in the frontal cortex. Pharmacol Biochem Behav 54, 143-7.

Invernizzi, R.W., 2013. Monitoring Extracellular Monoamines with In Vivo Microdialysis in Awake Rats: A Practical Approach, in: Di Giovanni, G., Di Matteo, V. (Eds.), Microdialysis Techniques in Neuroscience, Neuromethods. Humana Press, pp. 175-208.

Isoda, K., Morimoto, M., Matsui, F., Hasegawa, T., Tozawa, T., Morioka, S., Chiyonobu, T., Nishimura, A., Yoshimoto, K., Hosoi, H., 2010. Postnatal changes in serotonergic innervation to the hippocampus of methyl-CpG-binding protein 2-null mice. Neuroscience 165, 1254-1260. https://doi.org/10.1016/j.neuroscience.2009.11.036

Ito-Ishida, A., Ure, K., Chen, H., Swann, J.W., Zoghbi, H.Y., 2015. Loss of MeCP2 in Parvalbuminand Somatostatin-Expressing Neurons in Mice Leads to Distinct Rett Syndrome-like Phenotypes. Neuron 88, 651-658. https://doi.org/10.1016/j.neuron.2015.10.029

Katz, D.M., Berger-Sweeney, J.E., Eubanks, J.H., Justice, M.J., Neul, J.L., Pozzo-Miller, L., Blue, M.E., Christian, D., Crawley, J.N., Giustetto, M., Guy, J., Howell, C.J., Kron, M., Nelson, S.B., Samaco, R.C., Schaevitz, L.R., St Hillaire-Clarke, C., Young, J.L., Zoghbi, H.Y., Mamounas, L.A., 2012. Preclinical research in Rett syndrome: setting the foundation for translational success. Model Mech 5, 733-45. https://doi.org/10.1242/dmm.011007

Kilkenny, C., Browne, W.J., Cuthill, I.C., Emerson, M., Altman, D.G., 2010. Improving bioscience research reporting: the ARRIVE guidelines for reporting animal research. PLoS Biol 8, e1000412. https://doi.org/10.1371/journal.pbio.1000412

Klein, S.M., Vykoukal, J., Lechler, P., Zeitler, K., Gehmert, S., Schreml, S., Alt, E., Bogdahn, U., Prantl, L., 2012. Noninvasive in vivo assessment of muscle impairment in the mdx mouse model - A comparison of two common wire hanging methods with two different results. J. Neurosci. Methods 203, 292-297. https://doi.org/10.1016/j.jneumeth.2011.10.001

Krishnan, N., Krishnan, K., Connors, C.R., Choy, M.S., Page, R., Peti, W., Van Aelst, L., Shea, S.D., Tonks, N.K., 2015. PTP1B inhibition suggests a therapeutic strategy for Rett syndrome. J. Clin. Invest. 125, 3163-3177. https://doi.org/10.1172/JCl80323

Lombardi, L.M., Baker, S.A., Zoghbi, H., 2015. MECP2 disorders: from the clinic to mice and back. J Clin Invest 125, 2914-2923. https://doi.org/http://dx.doi.org/10.1172/JCI78167

Loubinoux, I., Tombari, D., Pariente, J., Gerdelat-Mas, A., Franceries, X., Cassol, E., Rascol, O., Pastor, J., Chollet, F., 2005. Modulation of behavior and cortical motor activity in healthy subjects by a chronic administration of a serotonin enhancer. Neurolmage 27, 299-313. https://doi.org/10.1016/j.neuroimage.2004.12.023

Maya Vetencourt, J.F., Sale, A., Viegi, A., Baroncelli, L., De Pasquale, R., O'Leary, O.F., Castren, E., Maffei, L., 2008. The antidepressant fluoxetine restores plasticity in the adult visual cortex. Science 320, 385-8. https://doi.org/320/5874/385 [pii] 10.1126/science.1150516

Mellios, N., Woodson, J., Garcia, R.I., Crawford, B., Sharma, J., Sheridan, S.D., Haggarty, S.J., Sur, M., 2014. beta2-Adrenergic receptor agonist ameliorates phenotypes and corrects 
microRNA-mediated IGF1 deficits in a mouse model of Rett syndrome. Proc Natl Acad Sci U A 111, 9947-52. https://doi.org/1309426111 [pii] 10.1073/pnas.1309426111

Meng, X., Wang, W., Lu, H., He, L.-J., Chen, W., Chao, E.S., Fiorotto, M.L., Tang, B., Herrera, J.A., Seymour, M.L., Neul, J.L., Pereira, F.A., Tang, J., Xue, M., Zoghbi, H.Y., 2016. Manipulations of MeCP2 in glutamatergic neurons highlight their contributions to Rett and other neurological disorders. eLife 5. https://doi.org/10.7554/eLife.14199

Miller, B.H., Schultz, L.E., Gulati, A., Cameron, M.D., Pletcher, M.T., 2008. Genetic regulation of behavioral and neuronal responses to fluoxetine. Neuropsychopharmacol. Off. Publ. Am. Coll. Neuropsychopharmacol. 33, 1312-1322. https://doi.org/10.1038/sj.npp.1301497

Morelli, E., Moore, H., Rebello, T.J., Gray, N., Steele, K., Esposito, E., Gingrich, J.A., Ansorge, M.S., 2011. Chronic 5-HT Transporter Blockade Reduces DA Signaling to Elicit Basal Ganglia Dysfunction. J. Neurosci. 31, 15742-15750. https://doi.org/10.1523/JNEUROSCI.2989-11.2011

Na, E.S., Nelson, E.D., Kavalali, E.T., Monteggia, L.M., 2013. The impact of MeCP2 loss- or gainof-function on synaptic plasticity. Neuropsychopharmacol. Off. Publ. Am. Coll. Neuropsychopharmacol. 38, 212-219. https://doi.org/10.1038/npp.2012.116

Nag, N., Berger-Sweeney, J.E., 2007. Postnatal dietary choline supplementation alters behavior in a mouse model of Rett syndrome. Neurobiol. Dis. 26, 473-480. https://doi.org/10.1016/j.nbd.2007.02.003

Osmon, K.J., Vyas, M., Woodley, E., Thompson, P., Walia, J.S., 2018. Battery of Behavioral Tests Assessing General Locomotion, Muscular Strength, and Coordination in Mice. J. Vis. Exp. 55491. https://doi.org/10.3791/55491

Panayotis, N., Ghata, A., Villard, L., Roux, J.C., 2011. Biogenic amines and their metabolites are differentially affected in the Mecp2-deficient mouse brain. BMC Neurosci 12, 47. https://doi.org/1471-2202-12-47 [pii] 10.1186/1471-2202-12-47

Philippe, T.J., Vahid-Ansari, F., Donaldson, Z.R., Le François, B., Zahrai, A., Turcotte-Cardin, V., Daigle, M., James, J., Hen, R., Merali, Z., Albert, P.R., 2018. Loss of MeCP2 in adult 5HT neurons induces 5-HT1A autoreceptors, with opposite sex-dependent anxiety and depression phenotypes. Sci. Rep. 8. https://doi.org/10.1038/s41598-018-24167-8

Popik, P., 1999. Preclinical pharmacology of citalopram. J. Clin. Psychopharmacol. 19, 4S-22S. https://doi.org/10.1097/00004714-199910001-00002

Riederer, P., Brücke, T., Sofic, E., Kienzl, E., Schnecker, K., Schay, V., Kruzik, P., Killian, W., Rett, A., 1985. Neurochemical aspects of the Rett syndrome. Brain Dev. 7, 351-360.

Robinson, L., Guy, J., McKay, L., Brockett, E., Spike, R.C., Selfridge, J., De Sousa, D., Merusi, C., Riedel, G., Bird, A., Cobb, S.R., 2012. Morphological and functional reversal of phenotypes in a mouse model of Rett syndrome. Brain J. Neurol. 135, 2699-2710. https://doi.org/10.1093/brain/aws096

Robinson, T.E., Whishaw, I.Q., 1988. Normalization of extracellular dopamine in striatum following recovery from a partial unilateral 6-OHDA lesion of the substantia nigra: a microdialysis study in freely moving rats. Brain Res 450, 209-24.

Ryabinin, A.E., Wang, Y.M., Finn, D.A., 1999. Different levels of Fos immunoreactivity after repeated handling and injection stress in two inbred strains of mice. Pharmacol. Biochem. Behav. 63, 143-151. https://doi.org/10.1016/s0091-3057(98)00239-1

Samaco, R.C., Mandel-Brehm, C., Chao, H.-T., Ward, C.S., Fyffe-Maricich, S.L., Ren, J., Hyland, K., Thaller, C., Maricich, S.M., Humphreys, P., Greer, J.J., Percy, A., Glaze, D.G., Zoghbi, H.Y., Neul, J.L., 2009. Loss of MeCP2 in aminergic neurons causes cell-autonomous defects in neurotransmitter synthesis and specific behavioral abnormalities. Proc. Natl. Acad. Sci. U. S. A. 106, 21966-21971. https://doi.org/10.1073/pnas.0912257106 
Samaco, R.C., McGraw, C.M., Ward, C.S., Sun, Y., Neul, J.L., Zoghbi, H.Y., 2013. Female Mecp2(+/-) mice display robust behavioral deficits on two different genetic backgrounds providing a framework for pre-clinical studies. Hum Mol Genet 22, 96-109. https://doi.org/dds406 [pii] 10.1093/hmg/dds406

Santarelli, L., Saxe, M., Gross, C., Surget, A., Battaglia, F., Dulawa, S., Weisstaub, N., Lee, J., Duman, R., Arancio, O., Belzung, C., Hen, R., 2003. Requirement of hippocampal neurogenesis for the behavioral effects of antidepressants. Science 301, 805-9.

Santos, M., Summavielle, T., Teixeira-Castro, A., Silva-Fernandes, A., Duarte-Silva, S., Marques, F., Martins, L., Dierssen, M., Oliveira, P., Sousa, N., Maciel, P., 2010. Monoamine deficits in the brain of methyl-CpG binding protein 2 null mice suggest the involvement of the cerebral cortex in early stages of Rett syndrome. Neuroscience 170, 453-467. https://doi.org/10.1016/j.neuroscience.2010.07.010

Sousa, N., Almeida, O.F.X., Wotjak, C.T., 2006. A hitchhiker's guide to behavioral analysis in laboratory rodents. Genes Brain Behav. 5, 5-24. https://doi.org/10.1111/j.1601183X.2006.00228.x

Stagni, F., Giacomini, A., Guidi, S., Ciani, E., Ragazzi, E., Filonzi, M., De lasio, R., Rimondini, R., Bartesaghi, R., 2015. Long-term effects of neonatal treatment with fluoxetine on cognitive performance in Ts65Dn mice. Neurobiol Dis 74, 204-18. https://doi.org/S09699961(14)00376-3 [pii] 10.1016/j.nbd.2014.12.005

Stuart, S.A., Robinson, E.S.J., 2015. Reducing the stress of drug administration: implications for the 3Rs. Sci. Rep. 5, 14288. https://doi.org/10.1038/srep14288

Tarquinio, D.C., Hou, W., Neul, J.L., Berkmen, G.K., Drummond, J., Aronoff, E., Harris, J., Lane, J.B., Kaufmann, W.E., Motil, K.J., Glaze, D.G., Skinner, S.A., Percy, A.K., 2018. The course of awake breathing disturbances across the lifespan in Rett syndrome. Brain Dev. https://doi.org/10.1016/j.braindev.2018.03.010

Toward, M.A., Abdala, A.P., Knopp, S.J., Paton, J.F., Bissonnette, J.M., 2013. Increasing brain serotonin corrects CO2 chemosensitivity in methyl-CpG-binding protein 2 (Mecp2)deficient mice. Exp Physiol 98, 842-9. https://doi.org/expphysiol.2012.069872 [pii] 10.1113/expphysiol.2012.069872

Ure, K., Lu, H., Wang, W., Ito-Ishida, A., Wu, Z., He, L.-J., Sztainberg, Y., Chen, W., Tang, J., Zoghbi, H.Y., 2016. Restoration of Mecp2 expression in GABAergic neurons is sufficient to rescue multiple disease features in a mouse model of Rett syndrome. elife 5. https://doi.org/10.7554/eLife.14198

Villani, C., Sacchetti, G., Bagnati, R., Passoni, A., Fusco, F., Carli, M., Invernizzi, R.W., 2016. Lovastatin fails to improve motor performance and survival in methyl-CpG-binding protein2-null mice. eLife 5, e22409. https://doi.org/10.7554/eLife.22409

Villani C., Sacchetti G., Castaldo A.M., Carli M., Invernizzi R.W., 2018. Motor coordination deficits and reduced levels of MeCP2 protein in motor brain regions of Mecp2 heterozygous mouse model of Rett syndrome are rescued by fluoxetine. Rett Syndrome Research, Toward The Future. Rome, Italy, September 27-29, 2018.

Vitrac, C., Benoit-Marand, M., 2017. Monoaminergic Modulation of Motor Cortex Function. Front. Neural Circuits 11, 72. https://doi.org/10.3389/fncir.2017.00072

Vogelgesang, S., Niebert, S., Renner, U., Möbius, W., Hülsmann, S., Manzke, T., Niebert, M., 2017. Analysis of the Serotonergic System in a Mouse Model of Rett Syndrome Reveals Unusual Upregulation of Serotonin Receptor 5b. Front. Mol. Neurosci. 10. https://doi.org/10.3389/fnmol.2017.00061

Zoghbi, H.Y., Milstien, S., Butler, I.J., Smith, E.O., Kaufman, S., Glaze, D.G., Percy, A.K., 1989. Cerebrospinal fluid biogenic amines and biopterin in Rett syndrome. Ann. Neurol. 25, 5660. https://doi.org/10.1002/ana.410250109 


\section{Supplementary Tables and Figures}

Table S1 Tryptophan levels in various brain regions of male Mecp2-null and WT mice.

\section{WT Mecp2-null}

Tryptophan $\mathrm{ng} / \mathrm{g}$ tissue $(\mathrm{n})$

\begin{tabular}{lll} 
Prefrontal cortex & $4677 \pm 1038(6)$ & $4413 \pm 484(6)$ \\
Hippocampus & $4396 \pm 670(7)$ & $4658 \pm 788(6)$ \\
Striatum & $5207 \pm 834(7)$ & $5793 \pm 961(6)$ \\
Brainstem & $4047 \pm 755(7)$ & $4185 \pm 698(6)$ \\
Remaining Cortex & $5093 \pm 830(7)$ & $5357 \pm 1030(6)$ \\
\hline
\end{tabular}

Data are mean \pm SEM.

Table S2 Fluoxetine (FLX) and norfluoxetine (NFLX) levels in plasma and brain of Mecp2deficient mice

PLASMA

\begin{tabular}{lccccc} 
& \multicolumn{2}{c}{ PLASMA } & \multicolumn{2}{c}{ BRAIN } \\
Genotype & $\begin{array}{c}\text { FLX dose } \\
(\mathbf{m g} / \mathbf{k g})\end{array}$ & $\begin{array}{c}\text { FLX } \\
(\mathbf{n g} / \mathbf{m L})\end{array}$ & \multicolumn{2}{c}{ NFLX } & \multicolumn{2}{c}{ NFLX } \\
\hline Mecp2 Het & 10 & $1329 \pm 97$ & $1690 \pm 147$ & $17.1 \pm 1.6$ & $21.7 \pm 2.0$ \\
Mecp2 null & 10 & $1076 \pm 132$ & $1053 \pm 35^{*}$ & $15.1 \pm 1.0$ & $13.8 \pm 1.6^{* *}$ \\
Mecp2 null & 20 & $1885 \pm 246$ & $1636 \pm 142$ & $37.0 \pm 2.2^{\star * *}$ & $31.9 \pm 1.5^{* \star}$ \\
\hline
\end{tabular}

Plasma and brain levels of fluoxetine and norfluoxetine were measured in Mecp2 Het and Mecp2 null mice receiving $10 \mathrm{mg} / \mathrm{kg}$ fluoxetine for 7 days. Mice were sacrificed $4 \mathrm{~h}$ after the last dose of the repeated schedule. Plasma in Mecp2 null mice given $20 \mathrm{mg} / \mathrm{kg} \mathrm{FLX,}$ was obtained from blood withdrawn from the maxillary sinus after 7 days of repeated injections. Brain tissue was collected from the same mice after 2-week treatment, $4 \mathrm{~h}$ after the last dose of FLX. Data are mean \pm SEM of 6-7 mice per group. ${ }^{*} p<0.05,{ }^{* *} p<$ $0.005,{ }^{* * *} p<0.0001$ vs. Mecp2 Het (Dunnett's test). 
Fig. S1A Body weight of Mecp2 HET and WT female and Mecp2 null and WT male mice over the 14-day treatment with $10 \mathrm{mg} / \mathrm{kg}$ fluoxetine (FLX) or vehicle (Veh), once daily. The same mice were evaluated in the rotarod as reported in Figs. 2 and 6, respectively.
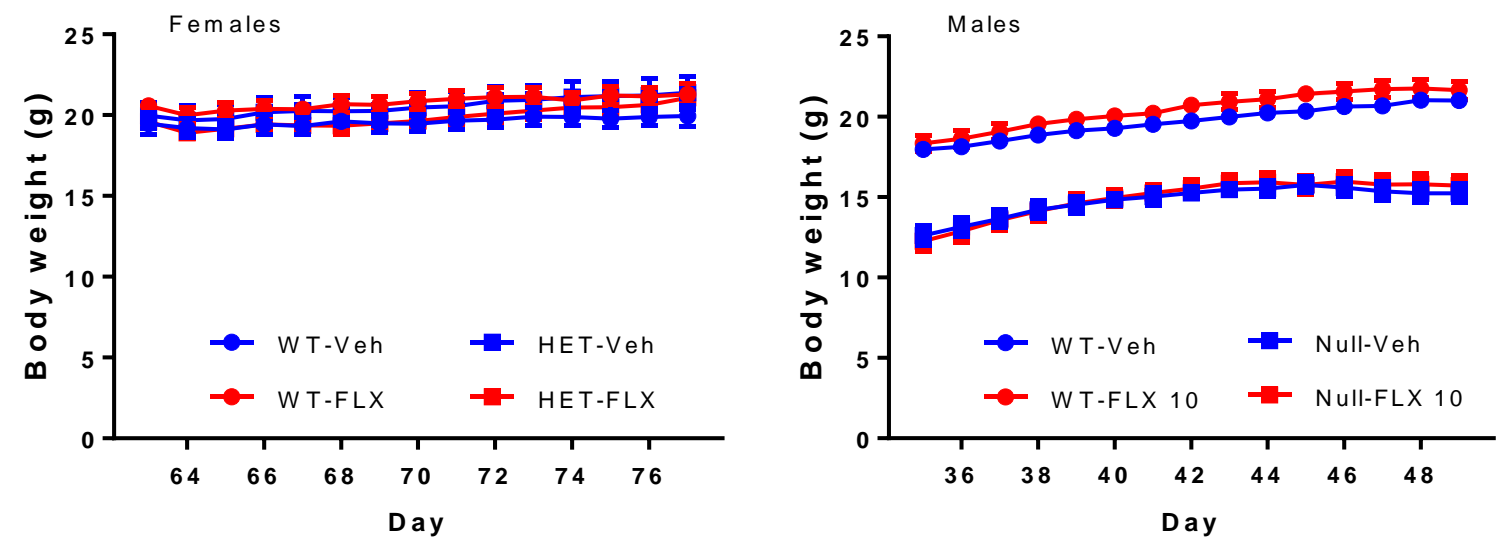

Fig. S1B Body weight of Mecp2 Het and WT mice receiving $20 \mathrm{mg} / \mathrm{kg}$ citalopram in drinking water or plain water. The same mice were evaluated in the rotarod as reported in Fig. 2

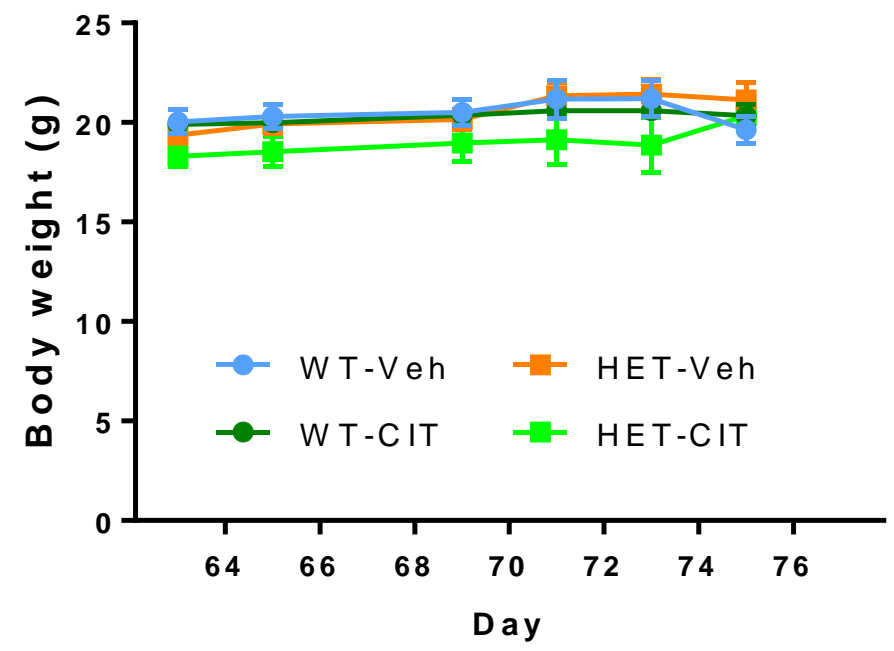



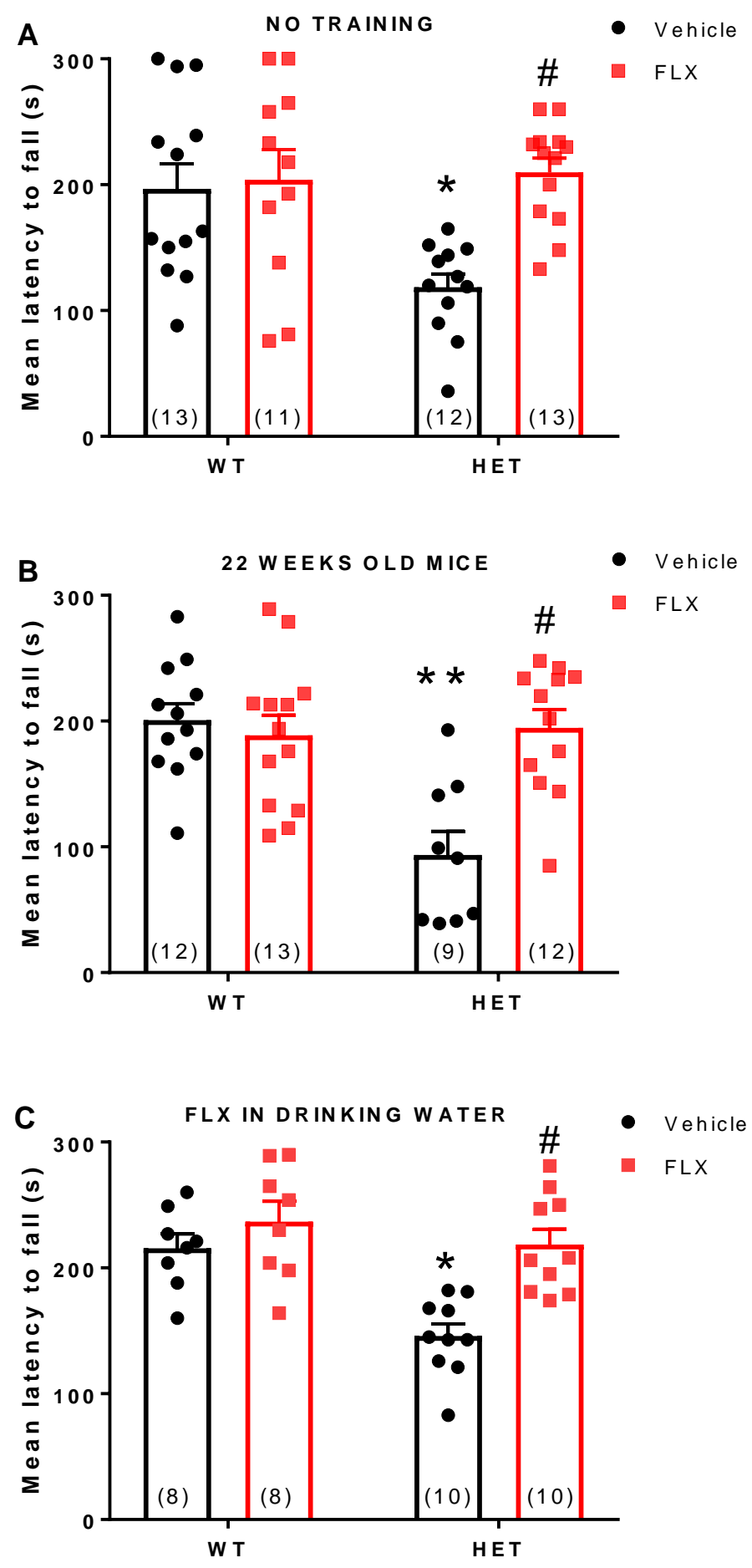

Fig. S2 The ability of fluoxetine in reversing motor deficits of Mecp2 Het (HET) mice is maintained under different experimental conditions: A) mice not pre-trained on the rotarod (ANOVA for treatment $F(1,45)=8.427, p=0.0057$; genotype $F(1,45)=4.532, p=$ 0.0388; genotype $x$ treatment $F(1,45)=6.137, p=0.0171) ; B)$ 22 weeks old mice (ANOVA for treatment, $F(1,42)=8.055, p=$ 0.0070 ; genotype $F(1,42)=$ $10.4, p=0.0024$; genotype $x$ treatment $F(1,42)=12.92, p=$ $0.0008)$; C) after administration of FLX in drinking water treatment (ANOVA for treatment, $F(1,32)=14.3, p=$ 0.0006; genotype $F(1,32)=$ 12.6, $p=0.0012$; genotype $x$ treatment $F(1,32)=4.321, p=$ 0.0457). WT and HET mice were given $10 \mathrm{mg} / \mathrm{kg} / \mathrm{day}$ fluoxetine or vehicle for 14 days. Data are the mean \pm SEM. The number of mice per group is shown in parentheses. ${ }^{*} p=$ $0.002,{ }^{* *} p<0.0007$ vs. WT-Veh; $\# p<0.02$ vs. HET-Veh (Sidak's test). 